\title{
Summary and Integration of Geophysical Investigations of the Tooele Army Depot (TEAD), Tooele, Utah
}

Open-File Report 2005-1338 


\section{Summary and Integration of Geophysical Investigations of the Tooele Army Depot (TEAD), Tooele, Utah}

By Theodore H. Asch

Open-File Report 2005-1338 


\section{U.S. Department of the Interior \\ Gale A. Norton, Secretary \\ U.S. Geological Survey \\ P. Patrick Leahy, Acting Director}

U.S. Geological Survey, Reston, Virginia: 2005

For product and ordering information:

World Wide Web: http://www.usgs.gov/pubprod

Telephone: 1-888-ASK-USGS

For more information on the USGS — the Federal source for science about the Earth,

its natural and living resources, natural hazards, and the environment:

World Wide Web: http://www.usgs.gov

Telephone: 1-888-ASK-USGS

\footnotetext{
Any use of trade, product, or firm names in this publication is for descriptive purposes only and does not imply endorsement by the U.S. Government.

This report has not been reviewed for stratigraphic nomenclature.

Although this report is in the public domain, permission must be secured from the individual copyright owners to reproduce any copyrighted materials contained within this report.

Suggested citation:

Asch, T.H., 2005, Summary and Integration of Geophysical Investigations of the Tooele Army Depot (TEAD), Tooele, Utah: U.S. Geological Survey Open-File Report 2005-1338, 46 p.
} 


\section{EXECUTIVE SUMMARY}

This report is a summary of the integration of the different geophysical investigations that have been performed to determine the depth to bedrock at the Tooele Army Depot (TEAD) near Tooele, Utah. The geophysical investigations discussed include the seismic, time-domain electromagnetic, gravity, and audio-magnetotelluric surveys. The primary purpose of these investigations was to investigate the depth to bedrock and the location of faults. This report provides an integration of the geophysical data with the available borehole information. The geophysical results, processing, and interpretation have been revisited from a data-integration point of view. Several inconsistencies became apparent between the different interpretations and with the borehole data. The various data sets were reexamined and the results were integrated into one interpretation. Site survey "coverage" (how much of the site was surveyed) was determined to be the main issue. The complicated and rapidly varying geology prevents full continuity of the geophysical interpretation of faulted blocks between the different lines and stations. A case is made for "wide-area" airborne electromagnetic and magnetic surveys of the Depot. These likely would result in a more comprehensive interpretation of the subsurface geology and, hence, the ground-water flow models in the vicinity of the Tooele Army Depot area. 


\section{Contents}

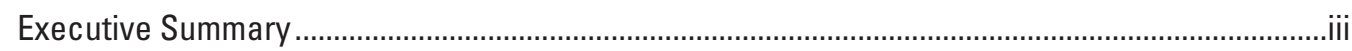

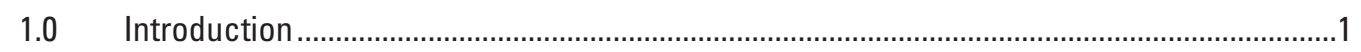

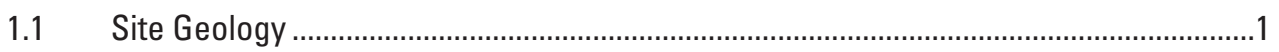

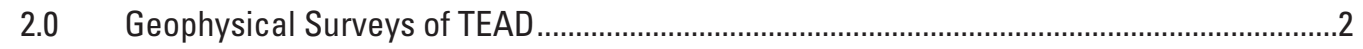

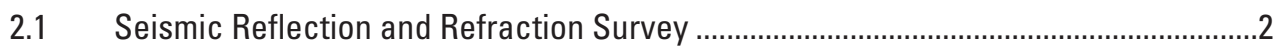

2.1.1 The Seismic Method ...........................................................................................2

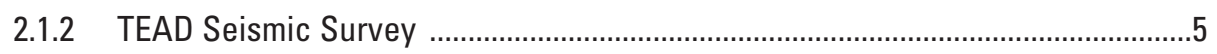

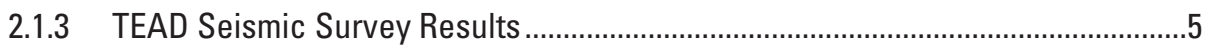

$2.2 \quad$ Time-Domain Electromagnetic (TEM) Survey .........................................................5

2.2.1 The Time-Domain Electromagnetic Method .......................................................

2.2.2 TEAD TEM Survey ..................................................................................

2.2.3 TEAD TEM Survey Results ..........................................................................

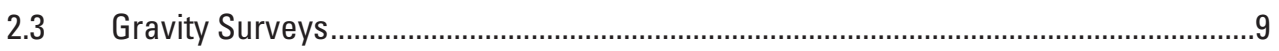

2.3.1 The Gravity Method (discussion after Kittner, 2003)..........................................

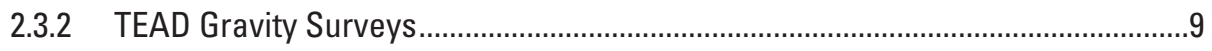

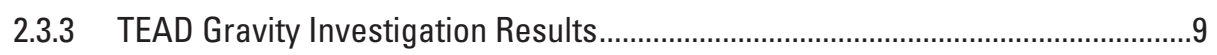

$2.4 \quad$ Audio-Magnetotelluric (AMT) Surveys .................................................................

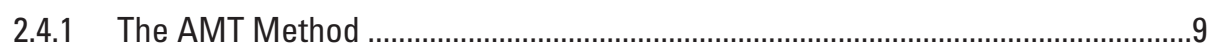

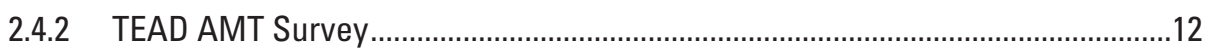

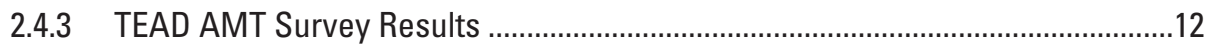

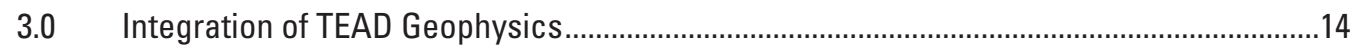

3.1 Seismic Base with Gravity, TEM, AMT, and Borehole ..............................................14

3.2 Gravity Base with TEM, AMT, and Borehole ...........................................................14

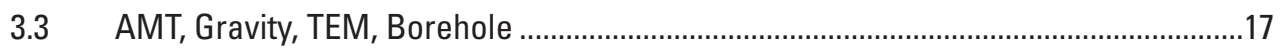

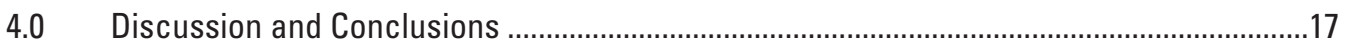

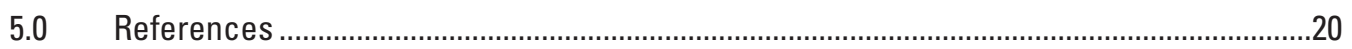

Appendix A Northwest Geophysics Associates 2-D Gravity Sections (fig. A1-A7) ........................21

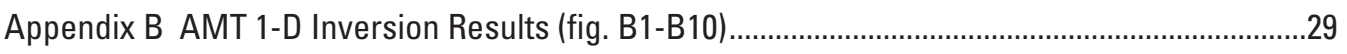

Appendix C AMT 2-D Inversion Results (fig. C1-C9) ................................................................38 


\section{Figures}

1. Location map of the Tooele Army Depot (TEAD) …….....................................................

2. Location of Sheley and $\mathrm{Yu}$ (2001) seismic refraction/reflection line (red) ........................3

3. Comparison of velocity tomogram, final stacked section (in depth), and depth migrated reflection section (from fig. 13, Sheley and $Y u, 2001$ ) ......................4

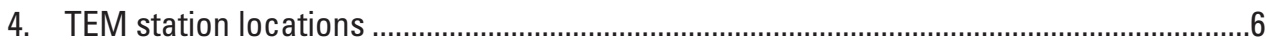

5. TEM bedrock elevation map ......................................................................................

6. Bedrock depth gravity interpretation of 2002 gravity data by Zhdanov and others,

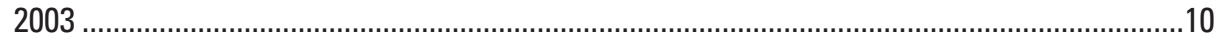

7. NGA bouguer gravity map of all gravity data $(1982,1986,2002,2003)$

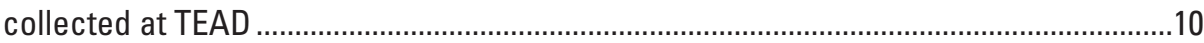

8. (pl.1). NGA, Inc. bedrock elevation map and final interpretation of all the gravity data collected to date at TEAD.........................................................................................11

9. Example of 2-D inversion modeling in Pellerin, 2004 (taken from fig. 6) .........................13

10. Seismic reflection results with interpreted bedrock depths from gravity, TEM, and AMT line crossings

11 (pl. 3). Interpreted gravity bedrock elevation map with seismic, TEM, and AMT results 18

12. (pl. 4). AMT-derived interpreted bedrock elevation map 19

\section{Plates}

1. Bedrock elevation map derived from gravity interpretation.

2. Depth migrated seismic reflection section including TEM- and AMT-interpreted depths.

3. Bedrock elevation map derived from gravity interpretation including faults inferred by AMT.

4. Bedrock elevation map derived from AMT interpretation.

\section{Tables}

1. TEM site locations and bedrock depth/elevations .......................................................

2. TEM site locations and original and reinterpreted bedrock depths and gravity and AMT interpreted depths. 


\section{Conversion Factors}

Inch/Pound to SI
\begin{tabular}{|l|c|l|}
\hline \multicolumn{1}{|c|}{ Multiply } & \multicolumn{1}{c|}{ By } & \multicolumn{1}{c|}{ To obtain } \\
\hline inch (in.) & 2.54 & centimeter (cm) \\
\hline inch (in.) & 25.4 & millimeter (mm) \\
\hline foot (ft) & 0.3048 & meter (m) \\
\hline mile (mi) & 1.609 & kilometer $(\mathrm{km})$ \\
\hline
\end{tabular}

\section{SI to Inch/Pound}

\begin{tabular}{|l|l|l|}
\hline \multicolumn{1}{|c|}{ Multiply } & \multicolumn{1}{c|}{ By } & \multicolumn{1}{c|}{ To obtain } \\
\hline centimeter $(\mathrm{cm})$ & 0.3937 & inch (in.) \\
\hline millimeter $(\mathrm{mm})$ & 0.03937 & inch (in.) \\
\hline meter $(\mathrm{m})$ & 3.281 & foot (ft) \\
\hline kilometer $(\mathrm{km})$ & 0.6214 & mile (mi) \\
\hline
\end{tabular}




\title{
Summary and Integration of Geophysical Investigations of the Tooele Army Depot (TEAD), Tooele, Utah
}

\author{
By Theodore H. Asch
}

\subsection{Introduction}

Many wells have been drilled, and several geophysical investigations including seismic, gravity, time-domain electromagnetic (TEM), and audio-magnetotelluric (AMT) have been conducted to determine ground-water flow and the depth to bedrock in the vicinity of the Tooele Army Depot. This report provides an integration of the different geophysical data with the available borehole information. The geophysical results, processing, and interpretation have been revisited from a data-integration point of view. Because the geophysical investigations were performed independently of one another, several inconsistencies became apparent between the different interpretations and also with the ground-truth well log and borehole data. The effort in the present study was to reexamine the different data sets from raw data through numerical inversion, delineate what was consistent and what was inconsistent with the other interpretations, try to determine the reason for the inconsistencies, reinterpret the inconsistent data sets, and finally integrate all the data sets into one comprehensive interpretation.

Section 1 is an introduction including a brief description of the local and regional geology. Section 2 of this report discusses each geophysical method utilized at the TEAD including a brief on the technique itself, the survey conducted at TEAD, the results, and any issues that became apparent with those results. Only highlights from the various surveys are presented here and only those that are used for the data interpretation and integration. Section 3 presents a discussion on the integration of the different geophysical interpretations and potential next steps. Section 4 presents conclusions on the utility of conducting geophysical investigations at TEAD. Note that this report uses both meters and feet to describe distance and depth. This is because while most geophysical measurements are made in units of meters, most others in the United States use feet to describe distances.

\subsection{Site Geology}

TEAD lies in the south end of Tooele Valley, a structural depression filled with unconsolidated and semiconsolidated basin fill sediments covering nearly 300 square miles. Mountains border the valley to the east, west and south, with the Great Salt Lake forming the northern boundary. To the east are north-trending Oquirrh Mountains, to the west are the Stansbury Mountains, and to the south lies South Mountain. The Mississippian to Permian Oquirrh Formation, consisting primarily of intercalated quartzite and limestone, is the major sequence of rocks composing the Oquirrh and South Mountains. The Stansbury Mountains are underlain by several formations, predominantly the Oquirrh Formation and the Cambrian Tintic Quartzite.

Tooele Valley is filled with Tertiary and Quaternary age basin sediments. These deposits range from clays to coarse gravels and represent a variety of depositional environments, including alluvial fan, near shore (beach), lacustrine, and fluvial. Along the east and southeast sides of the valley, a thick sequence of coarse sediments shed off the Oquirrh Mountains and form a thick sequence of coalescing alluvial fans. Subaerial and lacustrine depositional conditions alternated in the valley during the Tertiary and Quaternary as a result of climatic fluctuations. Basin fill sediments thicken to the north, reported to be greater than 8,000 feet in the northcentral part of the valley (Stokes, 1988).

Coarse-grained alluvial fan sediments are the main component of the basin fill material in the vicinity of TEAD. The most notable geologic feature is a shallow but largely buried bedrock block within the eastern portion of TEAD. The block is composed of Paleozoic interbedded quartzite, sandstone, and limestone. The bedrock high is a homoclinal ridge exposed over an elliptical-shaped area near the northeastern boundary of TEAD. Bedding strikes roughly east-northeast, which is approximately the orientation of the ridge, and dips to the north-northwest. Drilling evidence suggests that the northwest margin of the block is fault bounded. Geophysical data and drilling also suggest that the southeast margin of the block may be defined by a fault, and that the bedrock contact plunges to the south and the northeast beneath alluvial cover.

The area of investigation primarily lies in the northeast section of TEAD and extends off post to the north and east onto privately owned property (fig. 1). 


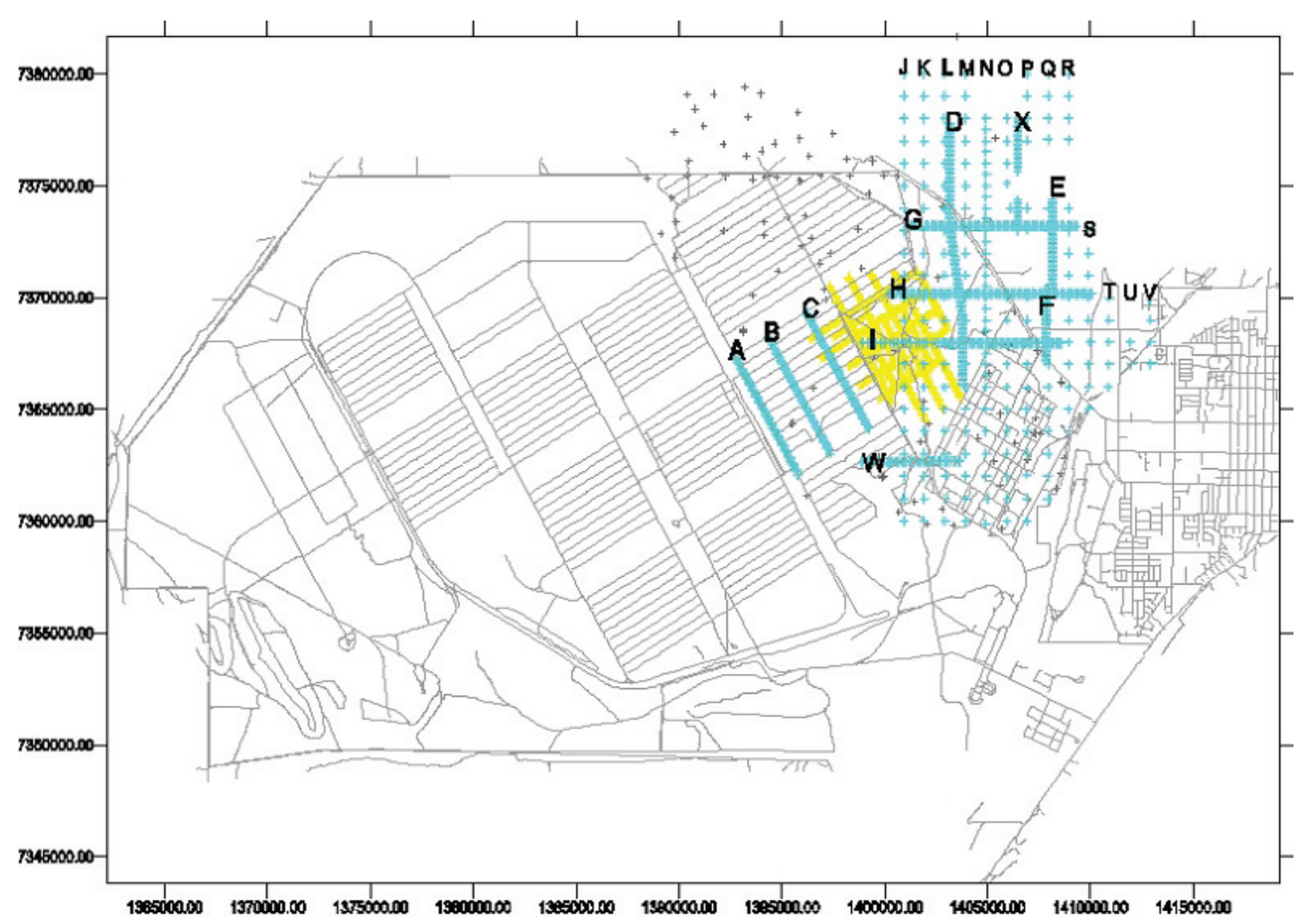

Figure 1. Location map of the Tooele Army Depot (TEAD). Area of interest is in the northeast. All crosses are data acquisition locations from the 2002-2003 field efforts. The 1986 data points are not shown in this figure except for the yellow lines. The separate 1986 data points are shown on figure 7 as small black squares. (From Kittner, 2003)

\subsection{Geophysical Surveys of TEAD}

This section presents a discussion of the different geophysical surveys that have been conducted at TEAD. These include seismic reflection and refraction surveys (Section 2.1), time-domain electromagnetic surveys (Section 2.2), gravity surveys (Section 2.3), and audio-magnetotelluric surveys (Section 2.4). All the surveys included Field Geologist, Carl Cole, of the U.S. Army Corps of Engineers (USACE), Sacramento District, who is on full-time assignment at Tooele Army Depot. Mr. Cole provided the field crews access to and from the secure areas of TEAD, helped establish the lines and grid points for the surveys, and assisted with the field data collection.

\subsection{Seismic Reflection and Refraction Survey}

\subsubsection{The Seismic Method}

A near-surface geophysical seismic survey utilizes a sledgehammer or heavier, truck-mounted weight to generate seismic waves and propagate them through the ground. Receivers, usually vertical-component geophones, are arrayed on the surface of the ground at some set interval and record the time the seismic waves take to travel from the source location through the ground to the receiver location. This seismic travel time is dependent on the materials that the waves pass through. The seismic energy travels faster in some materials than in others. When a seismic wave 


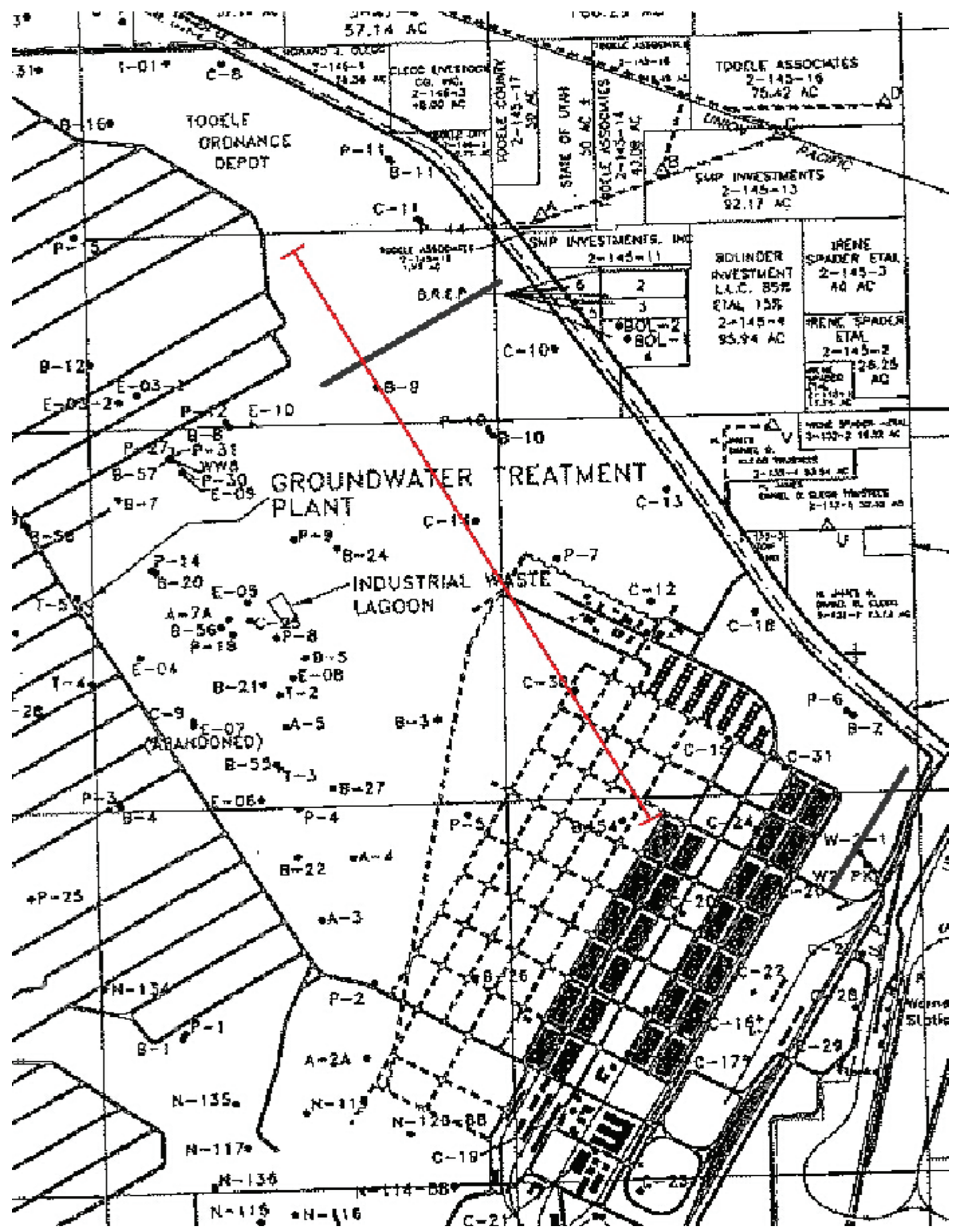

Figure 2. Location of seismic refraction/reflection line (red). Figure taken from figure 1 in Sheley and Yu (2001). The total line length is 2,640 m (1.64 mi.). Sources were placed every $2.5 \mathrm{~m}$. and receivers every $5 \mathrm{~m}$. North is at the top of the map. 

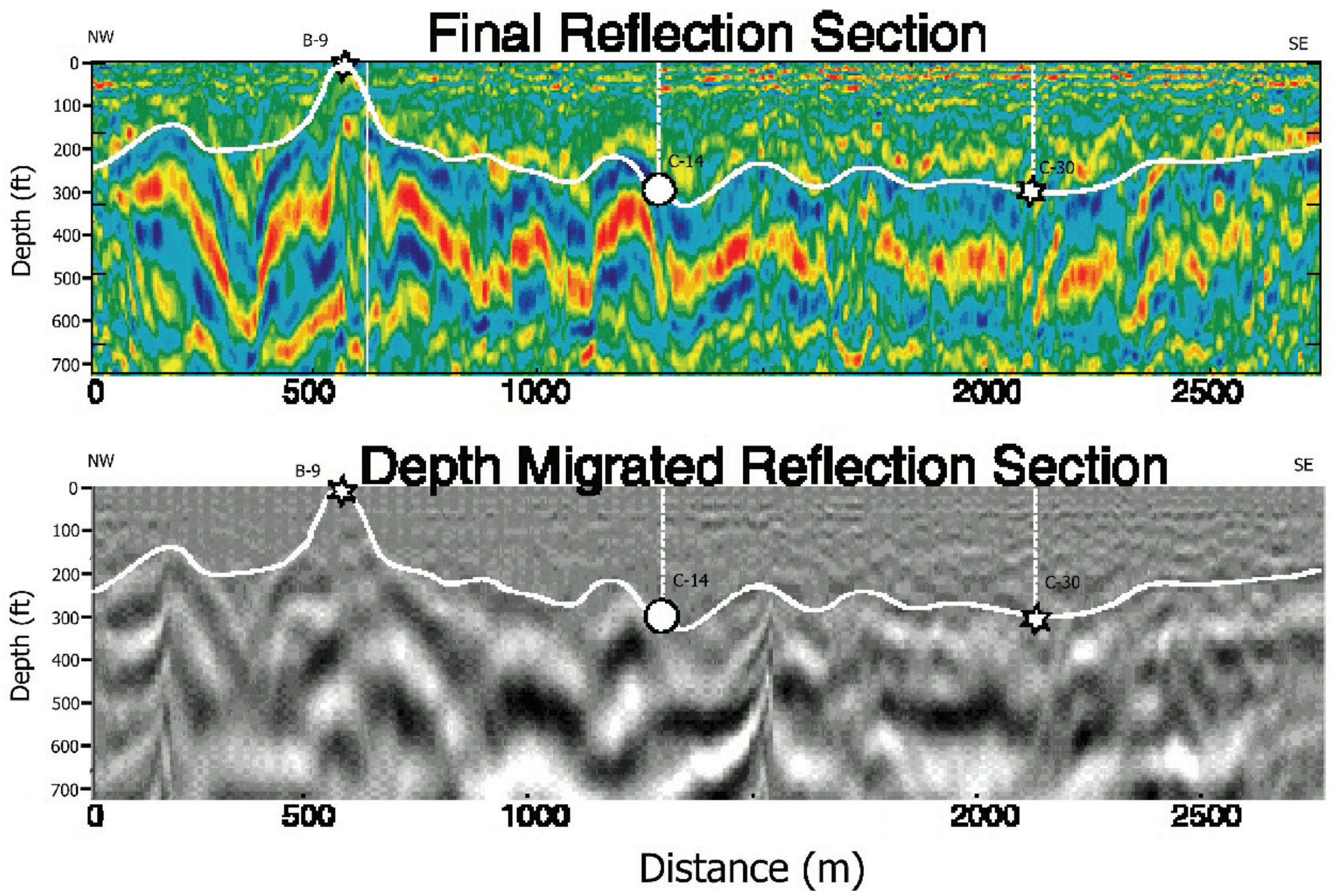

Figure 3 (from fig. 13, Sheley and Yu, 2001). Comparison of final stacked section (in depth) on the top and depth migrated reflection section on the bottom. Labeled well locations are denoted with symbols. Stars indicate locations where wells intersected bedrock. The circles denote the location and depth of well C-14, which did not encounter bedrock. Sheley and Yu's interpretation of bedrock is drawn as the sinuous white line. 
encounters an interface between two different rock types, some of the energy will be reflected off the surface of the second rock type. The remainder will continue on its way, but the ray path has a different angle depending on the material. The path the seismic energy is traveling will have been bent (refraction). Compiling the travel times from each of the different sources and receiver geophones results in several travel-time sections. After these travel-time data are filtered for noise and numerically processed, a spatial depth section of the subsurface geology is developed based on the different seismic reflectors.

\subsubsection{TEAD Seismic Survey}

Reflection and refraction seismic surveys were conducted at TEAD in 2000 and 2001 by Sheley and Yu (2001) along a northwest to southeast trending transect $2.64 \mathrm{~km}$ long (1.64 miles) (red line on fig. 2). The transect passed over wells B-9 (bedrock at $24 \mathrm{ft}$ ), C-14 (borehole did not penetrate basement; thus, bedrock must be below $300 \mathrm{ft}$.), and well C-30 (bedrock at $297 \mathrm{ft}$ ). A 500-pound truck-mounted weight was used at 2.5$\mathrm{m}$ intervals, and 120 geophones were placed at 5-m intervals. Reflection processing produced a stacked section, and firstarrival refraction tomography produced a velocity tomogram.

\subsubsection{TEAD Seismic Survey Results}

The final results are presented on figure 3 (from fig. 13 in Sheley and Yu, 2001 report). While Sheley and Yu (2001) worked in units of meters, the vertical scale in the figure has been modified to reflect depth in feet. The white line on figure 3 represents Sheley and Yu's interpretation of the top of the bedrock. The sharp, continuous reflectors in the basement between $0 \mathrm{~m}$ and $1,500 \mathrm{~m}$ may indicate that this area is more competent than between 1,500 $\mathrm{m}$ and 2,600 $\mathrm{m}$ where the orange reflector, while still present, is much more broken up. Generally, these seismic results are quite good in that the shallower subhorizontal sands and gravels are evident near the ground surface, and the basement appears to be quite folded (orange and blue horizons in upper section). Faults in the folded (dipping?) basement may be approximately inferred by the discontinuous data at $200 \mathrm{~m}, 600 \mathrm{~m}, 1,500 \mathrm{~m}$, and possibly at 2,100 $\mathrm{m}$ distance along the line. The stars at approximately $600 \mathrm{~m}$ and 2,100 $\mathrm{m}$ are wells B-9 and C-30, respectively, and the white circle at approximately $1,200 \mathrm{~m}$ is well C-14.

The only reexamination 'issue' with this seismic survey is the placement of the white line. The line initially $(<1000 \mathrm{~m})$ lies above the strong reflectors in the basement and separates it from the shallower gravels. However, southeast of approximately $1,000 \mathrm{~m}$, the white line appears to be within what would appear to be the top of the basement. It appears that the line is "forced" to dive under well C-14 in order to meet the requirement that $\mathrm{C}-14$, when drilled, did not intersect bedrock. The white line passes through what would appear to be a good reflector at 1,100 $\mathrm{m}$ distance. The folded-appearing reflection horizons above the white bedrock line and below the horizontal alluvial layers likely are reflections off incompetent, weathered bedrock.

\subsection{Time-Domain Electromagnetic (TEM) Survey}

\subsubsection{The Time-Domain Electromagnetic Method}

The Time-Domain, or Transient, Electromagnetic (TEM) method uses a transmitter to inject a pulse of current into a large loop of wire. The transmitter loops may be circular or square in shape and can range in diameter from ten meters to several hundred meters. A smaller receiving loop (or coil) is used to detect the time-varying, decaying magnetic field that is induced in the earth. The receiver-coil voltage output is recorded, and the transient decay curve is numerically modeled using a onedimensional (flat layers) model representation. The result is a determination of the electrical resistivity of the ground versus depth at each site. Pumps in wells and local buried and overhead power lines can adversely affect the TEM method.

\subsubsection{TEAD TEM Survey}

The University of Arizona conducted a TEM survey at TEAD in 2000 (Sternberg and others, 2000). Approximately 36 soundings were made (fig. 4). The station-numbering scheme is related to data-set lines and stations along that line. If the first station of data set one is Set 1, Station 1, then the station number is 11 . Set 1 , Station 2 would be station 12. Set 6 , station 1 is station number 61 and so forth. The distribution of stations in the area suggests that the power lines along Highway 112, fences, and buried pipelines probably were a factor in where reliable data could be acquired.

A $200 \mathrm{~m}$ by $200 \mathrm{~m}$ square transmitter loop was used. Receiver measurements were made in the center of the large loop using an induction coil (magnetometer). These types of measurements are known as "central induction resistivity soundings".

\subsubsection{TEAD TEM Survey Results}

"Smooth" one-dimensional modeling was performed on the TEM data, a bedrock interface was determined, and an elevation contour map developed. Initially, well log data were not included in the initial interpretation but were later added. The resulting TEM bedrock elevation map is presented on figure 5. Note the deepening of the bedrock to the northeast. Table 1 lists the bedrock depths and elevations used to produce the map on figure 5 .

Reexamination of the raw data and 1-D modeling results contained in the Sternberg and others (2000) report indicates that the TEM survey was conducted per standard industry practice. One-dimensional modeling is the current state of interpretation for TEM data. Most other electromagnetic methods have 2-D and some methods have 3-D modeling and inversion capabilities. As each of the 1-D modeling results were reexamined, it became apparent, based on well log and 


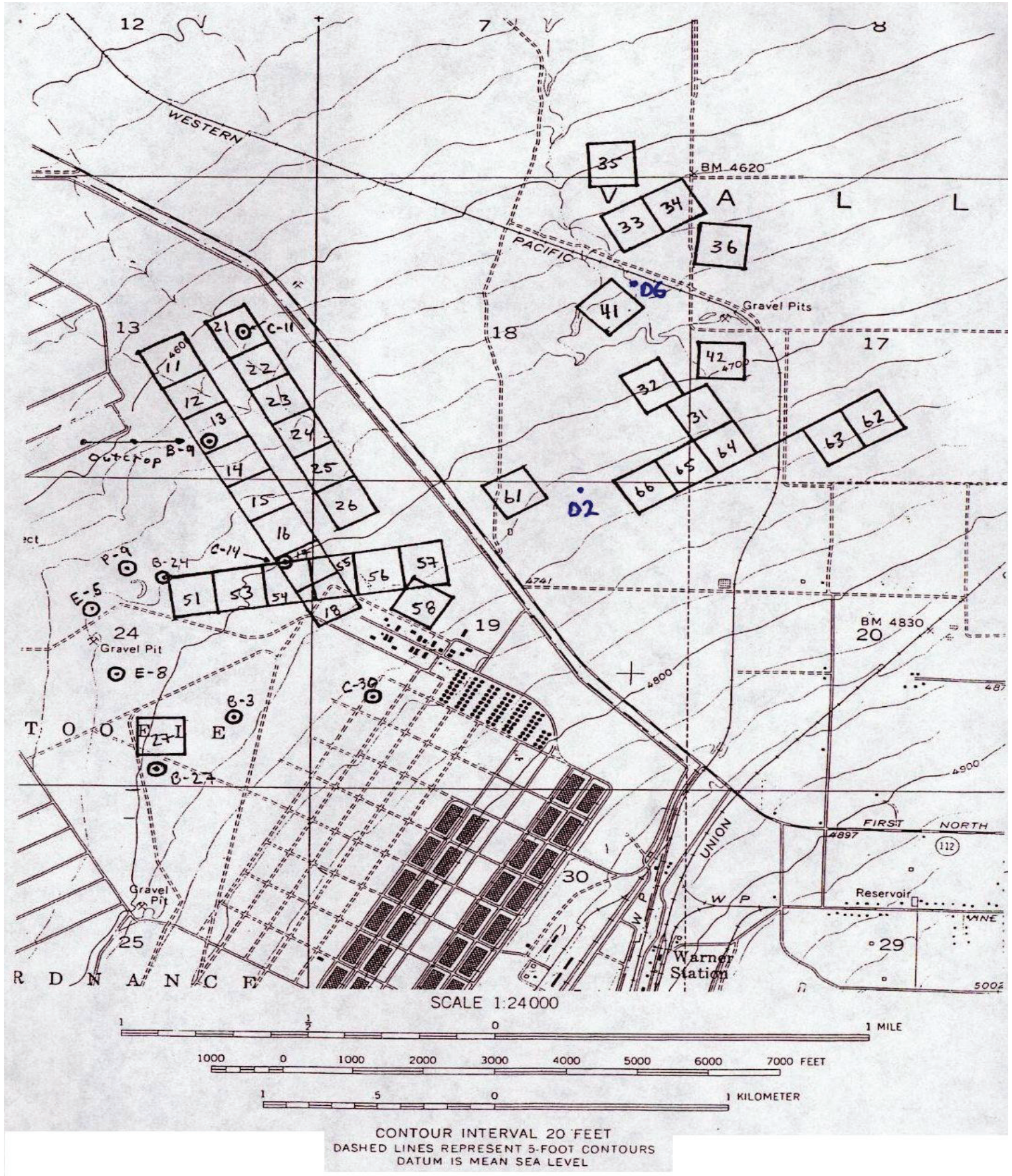

Figure 4. TEM station locations. Taken from figure 1 in Sternberg and others, 2000. Some wells are marked.

drilling information and subsequent integration with the gravity interpretation, that different horizons possibly should be selected as representing bedrock. This is especially true for TEM stations 13-16 near B-9 (fig. 4 and 5) and stations 51-56 located in the vicinity of B-24. At B-9, bedrock is encountered at 24 feet and 162 feet at B-24. TEM stations 13 and 14 are on either side of B-9. 


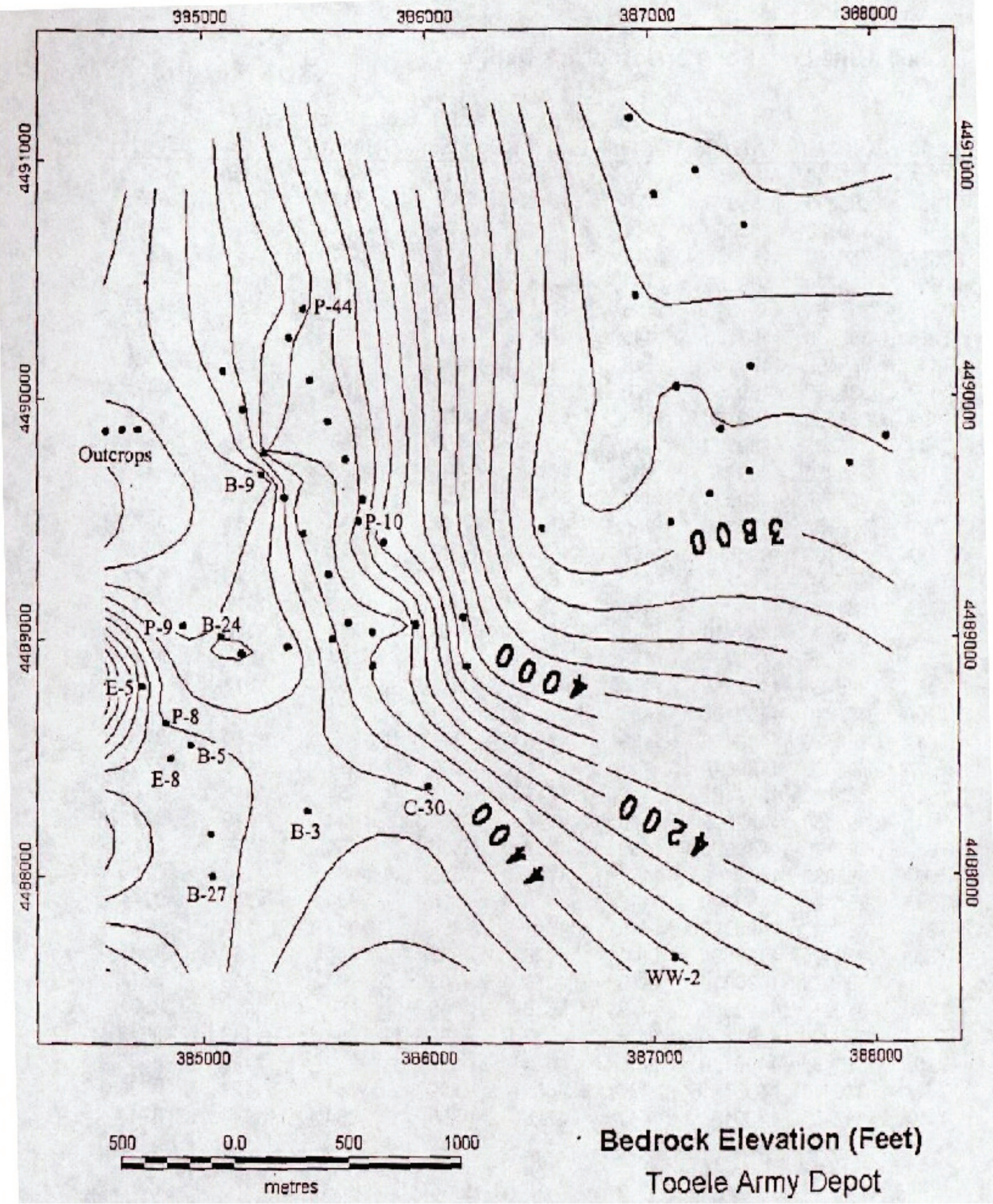

Figure 5. TEM bedrock elevation map. Taken from Sternberg and others, 2000, figure 13. 
Table 1. TEM site locations (see fig. 4) and bedrock depth/elevations (from Sternberg and others, 2000)

\section{Surface Surface Bed Rock Bed Rock Bed Rock Bed Rock}

Station X(UTM) Y (UTM) Elev (m) Elev (ft) Depth (m) Depth (ft) Elev (m) Elev (ft)

\begin{tabular}{|c|c|c|c|c|c|c|c|c|}
\hline T51A & 385180 & 4488940 & 1438 & 4718 & -49 & -161 & 1389 & 4557 \\
\hline T53A & 385380 & 4488970 & 1438 & 4718 & -51 & -167 & 1387 & 4551 \\
\hline T54A & 385580 & 4489000 & 1446 & 4744 & -108 & -354 & 1338 & 4390 \\
\hline T55A & 385760 & 4489030 & 1444 & 4738 & .114 & -374 & 1330 & 4364 \\
\hline T56A & 385950 & 4489060 & 1443 & 4734 & -114 & -374 & 1329 & 4360 \\
\hline T57A & 386160 & 4489090 & 1445 & 4741 & -207 & -679 & 1238 & 4062 \\
\hline TB27 & 385040 & 4488180 & 1440 & 4725 & -86 & -282 & 1354 & 4442 \\
\hline T11A & 385100 & 4490120 & 1415 & 4643 & -54 & -177 & 1361 & 4465 \\
\hline $\mathrm{T} 12 \mathrm{~A}$ & 385190 & 4489960 & 1420 & 4659 & -50 & -164 & 1370 & 4495 \\
\hline T13A & 385280 & 4489780 & 1430 & 4692 & -106 & -348 & 1324 & 4344 \\
\hline T14A & 385365 & 4489590 & 1433 & 4702 & -108 & -354 & 1325 & 4347 \\
\hline T15A & 385450 & 4489440 & 1437 & 4715 & -99 & -325 & 1338 & 4390 \\
\hline T16A & 385560 & 4489270 & 1443 & 4734 & -111 & -364 & 1332 & 4370 \\
\hline T17A & 385650 & 4489070 & 1450 & 4757 & -117 & -384 & 1333 & 4374 \\
\hline T18A & 385760 & 4488890 & 1451 & 4761 & -137 & -449 & 1314 & 4311 \\
\hline $\mathrm{T} 21 \mathrm{~A}$ & 385390 & 4490260 & 1412 & 4633 & -87 & -285 & 1325 & 4347 \\
\hline T22A & 385480 & 4490080 & 1413 & 4636 & .96 & -315 & 1317 & 4321 \\
\hline T23A & 385560 & 4489910 & 1425 & 4675 & -99 & -325 & 1326 & 4351 \\
\hline $\mathrm{T} 24 \mathrm{~A}$ & 385640 & 4489750 & 1428 & 4685 & -111 & -364 & 1317 & 4321 \\
\hline$T 25 A$ & 385720 & 4489580 & 1431 & 4695 & -118 & -387 & 1313 & 4308 \\
\hline $\mathrm{T} 26 \mathrm{~A}$ & 385810 & 4489400 & 1435 & 4708 & -171 & -561 & 1264 & 4147 \\
\hline T61A & 386520 & 4489460 & 1438 & 4718 & -288 & -945 & 1150 & 3773 \\
\hline T62A & 388060 & 4489840 & 1442 & 4731 & -300 & -984 & 1142 & 3747 \\
\hline T63A & 387900 & 4489725 & 1446 & 4744 & -300 & -984 & 1146 & 3760 \\
\hline T64A & 387450 & 4489690 & 1449 & 4754 & -300 & -984 & 1149 & 3770 \\
\hline T65A & 387270 & 4489600 & 1450 & 4757 & -300 & -984 & 1150 & 3773 \\
\hline$T 66 A$ & 387090 & 4489480 & 1452 & 4764 & -300 & -984 & 1152 & 3780 \\
\hline T31A & 387320 & 4489870 & 1441 & 4728 & -300 & -984 & 1141 & 3744 \\
\hline T32A & 387120 & 4490050 & 1445 & 4741 & -300 & -984 & 1145 & 3757 \\
\hline T58A & 386175 & 4488885 & 1441 & 4728 & -202 & -663 & 1239 & 4065 \\
\hline T33A & 387025 & 4490850 & 1419 & 4656 & -300 & -984 & 1119 & 3671 \\
\hline T34A & 387210 & 4490950 & 1419 & 4656 & -300 & -984 & 1119 & 3671 \\
\hline T35A & 386920 & 4491170 & 1412 & 4633 & -300 & -984 & 1112 & 3648 \\
\hline T36A & 387430 & 4490720 & 1415 & 4643 & -300 & -984 & 1115 & 3658 \\
\hline T41A & 386940 & 4490430 & 1427 & 4682 & -300 & -984 & 1127 & 3698 \\
\hline $\mathrm{T} 42 \mathrm{~A}$ & 387455 & 4490130 & 1441 & 4728 & -300 & -984 & 1141 & 3744 \\
\hline
\end{tabular}




\subsection{Gravity Surveys}

\subsubsection{The Gravity Method (discussion after Kittner, 2003)}

Gravity methods measure variations of gravity at the earth's surface. By analyzing these variations, the densities of subsurface materials can be determined. Only the vertical component of force is measured. This requires the measuring device to be perfectly level. The unit of measure is the milligal, abbreviated mGal, and is equal to $1 * 10-3 \mathrm{Gal}$. Among geophysicists, an acceleration of $1 \mathrm{~cm} / \mathrm{sec} 2$ is referred to as the Gal, in honor of Galileo. The gravitational acceleration at the earth's surface is about $9.8 \mathrm{~m} / \mathrm{sec} 2$, or $980 \mathrm{Gal}$. But in gravity exploration work, differences often are measured to one-ten millionth or less of the earth's field and so the mGal became the standard unit (Burger, 1992).

In most gravity surveys, the quantity actually observed is not the earth's true gravitational attraction but its variation from one point to another. These lateral differences are more easily measured than the total gravitational field. Many types of rocks have characteristic ranges of density that may differ from those of other types that are laterally adjacent. Thus, an anomaly in the earth's gravitational attraction often can be related to a buried geological feature or lateral changes in the geology from one set of measurements to another.

\subsubsection{TEAD Gravity Surveys}

Several gravity surveys have been performed at TEAD including measurements in 1982, 1986, 2002, and 2003. Kittner (2003) discusses each of these data sets in detail. The purpose of the 2003 gravity survey was to act as a 'tie-line' between each of the different data sets. That is, develop a method by which all of the gravity data can be normalized to one correct value. The 2003 survey was conducted, in part, in response to a request by researchers at the University of Utah Geology and Geophysics Department (Zhdanov et al. 2003) who had been contracted to process and interpret about 1,000 data points from the different sets of gravity data.

\subsubsection{TEAD Gravity Investigation Results}

Figure 6 presents the Zhdanov (2003) interpretation of the 2002 gravity data. This interpretation was completed prior to the acquisition of the additional 2003 stations.

In 2004, to refine this interpretation, the gravity data were given to Northwest Geophysical Associates who are based in Corvallis, Oregon. Their job was to combine, reduce, and examine all the available 1982, 1986, 2002, and 2003 data. They reported that the primary difficulty with reducing the data was determining and removing the variations in the regional gradient. Once that was done, they were able to produce the bouguer-corrected gravity map shown on figure 7. Removing the regional gradient from the bouguer data results in the final bedrock elevation map that is shown on figure 8 (also on attached pl. 1). The bedrock high is evident as a southwest-northeast trending high. Note also the bedrock low along the same lineation and the indication of northwestsoutheast trending lineations. Depth cross-sections also were developed from this map. These are included in Appendix A along with an index map of the cross-section locations.

While the elevation contours on figure 8 are more indicative of faulting around the bedrock high than what is shown on figure 6 , it still would be hard to definitively locate the faults. This doesn't mean the gravity data are flawed but rather is due to the nature of the gravitational field that is being measured. What is observed in a gravitational field measurement is the result of combining all the density effects of all the geology in the area around the measurement point. Thus, each observation is an averaging of the effects of the varying densities on the gravitational field. The gravity modeler tries to decipher what is in the ground by assigning various densities to different bodies in the ground. Only the largest faults can be clearly delineated by measurements of the gravitational field. Another geophysical technique is required to better delineate the faults in the subsurface.

\subsection{Audio-Magnetotelluric (AMT) Surveys}

\subsubsection{The AMT Method}

The MT method is a passive surface geophysical technique that uses the Earth's natural electromagnetic fields to investigate the electrical resistivity structure of the subsurface. The resistivity of geologic units is dependent largely upon their fluid content, porosity, degree of fracturing, temperature, and conductive mineral content (Keller, 1989). Saline fluids within the pore spaces and fracture openings can reduce resistivities in a resistive rock matrix. Electrical resistivity also can be lowered by the presence of conductive clay minerals, carbon, and metallic mineralization. Carbonate rocks are moderately to highly resistive (hundreds to thousands of ohm-m) depending upon their fluid content, porosity, fracturing, and impurities. Marine shales, mudstones, and clay-rich alluvium normally are conductive (a few ohm-m to tens of ohm-m). Unaltered metamorphic rocks (nongraphitic) are moderately to highly resistive (hundreds to thousands of ohm$\mathrm{m})$. Tables of electrical resistivity for a variety of rocks, minerals, and geological environments are included in Keller (1987) and Palacky (1987).

The MT method can be used to probe the crust from depths of tens of meters to depths of tens of kilometers (Vozoff, 1991). Natural variations of the Earth's magnetic and electric field are measured and recorded at each MT station. The natural electric and magnetic fields are recorded in two orthogonal, horizontal directions. The resulting time-series signals are used to derive apparent resistivities and phases. For a two-dimensional (2-D) Earth, the MT fields can be decoupled into transverse electric (TE) and transverse magnetic (TM) modes; 2-D modeling generally is done to fit both 


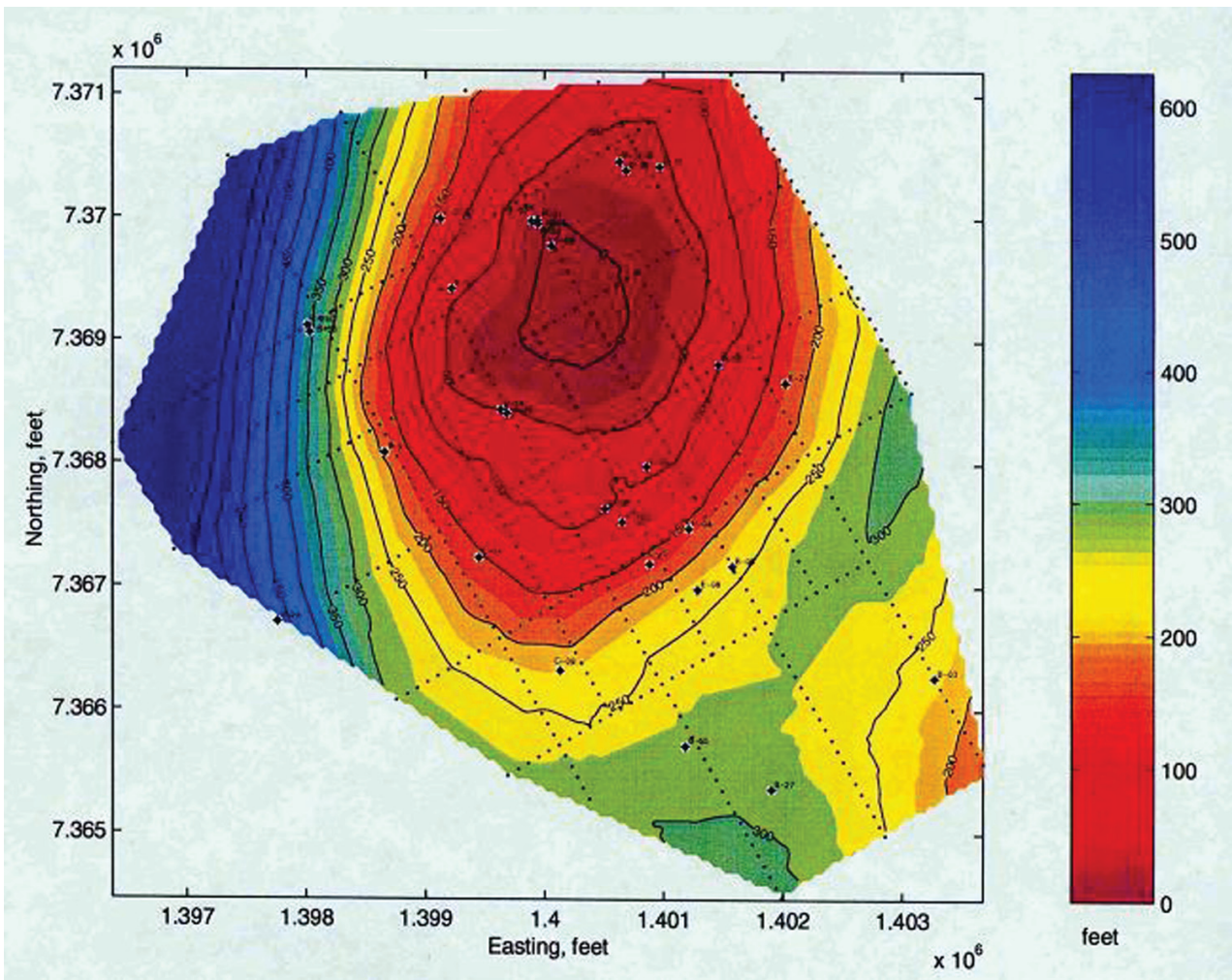

Figure 6. Bedrock depth gravity interpretation of 2002 gravity data by Zhdanov and others, 2003.

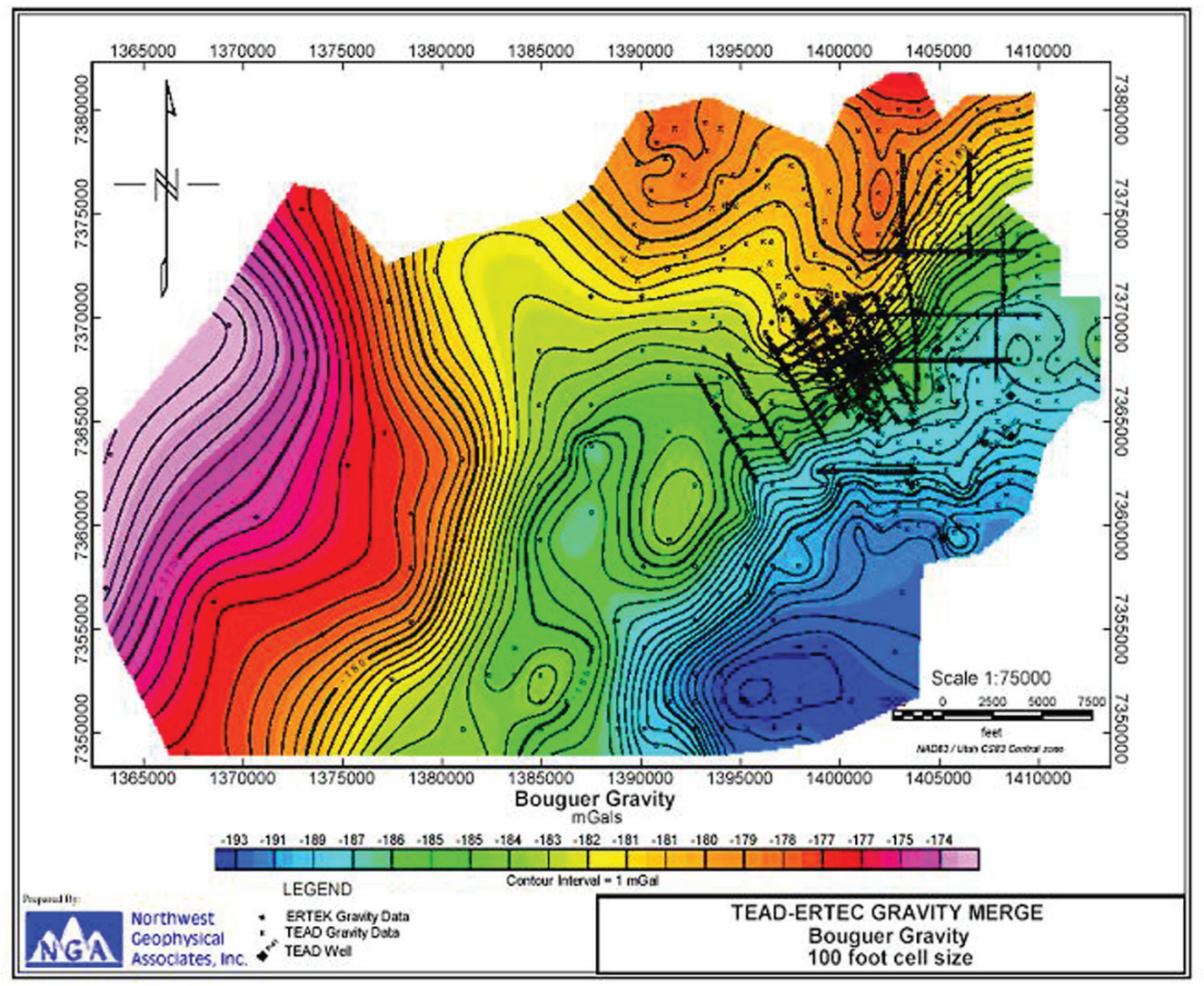

Figure 7. NGA bouguer gravity map of all gravity data $(1982,1986,2002,2003)$ collected at TEAD. Black x's and squares are gravity locations including AMT Lines A, C, D, E, F, G, H, I, and X. (Carl Cole personal commun. by email, dated 09 November 2004) 


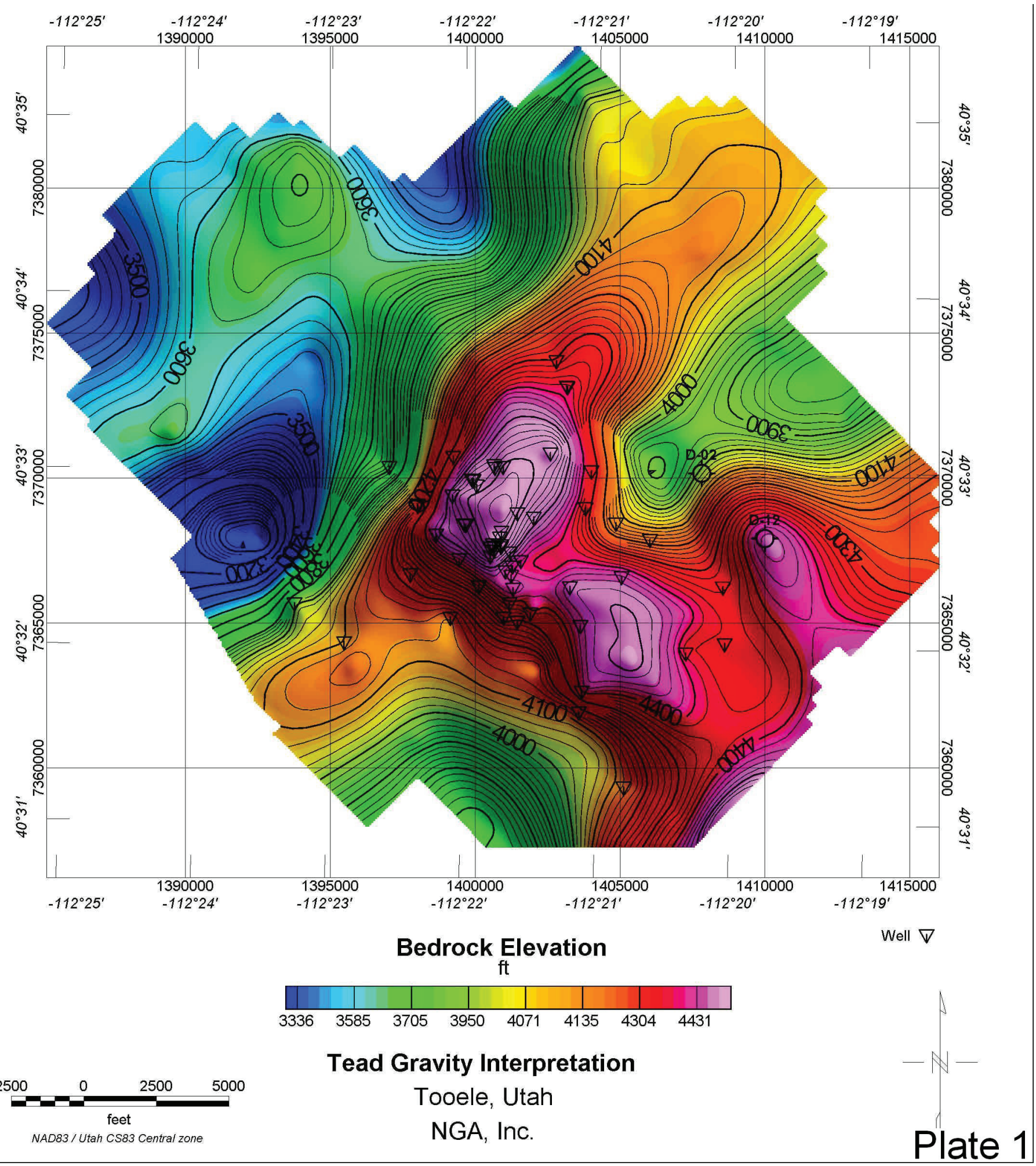

Figure 8 (pl.1). NGA, Inc. bedrock elevation map and final interpretation of all the gravity data collected to date at TEAD. The inverted triangles are boreholes/wells that were reported to have intersected bedrock. (Carl Cole personal commun. by email, dated 29 0ctober 2004) 
modes. When the geology satisfies the 2-D assumption, the MT data for the TE mode are for the electric field parallel to geologic strike, and the data for the TM mode are for the electric field across strike. The MT method is well suited for studying complicated geological environments because the electric and magnetic relations are sensitive to vertical and horizontal variations in resistivity.

High-frequency (audio) magnetotellurics (AMT) images the shallow stratigraphy, alluvium-bedrock contact, and bedrock structure associated with fracture zones. Traditionally, the AMT technique was limited by the lack of natural high-frequency electric fields. However, newer AMT systems augment the natural electric fields by providing additional bandwidth with a small transmitter in the range of $1 \mathrm{kHz}$ (where natural signals are normally weak) to $23 \mathrm{kHz}$. With this system, variations in ground conductivity can be investigated from a few tens of meters to several 100 meters depth.

\subsubsection{TEAD AMT Survey}

In the fall of 2002, an AMT survey, using the Geometrics STRATAGEM, was conducted by geophysicists from USACE, Sacramento on Lines A, C, D, E, F, G, H, I, and X. These lines are identified on Appendix B, figure B-1 and geolocated at TEAD on figure 7. Data were nominally acquired every $200 \mathrm{ft}$ using the standard orthogonal E, $\mathrm{H}$ arrangement. The $\mathrm{x}$-direction was set along the line and the y-direction was set perpendicular to the line. Electric and magnetic fields were measured using 15-m dipoles and EMI BF-6 high frequency magnetic induction coils. Time-series data were recorded and field processed into cross-powers in real time by the STRATAGEM. Some poor quality data were caused by local power lines close to Highway 112 and by a buried cathode-protected pipe crossing Line G. These were repeated as necessary.

\subsubsection{TEAD AMT Survey Results}

The AMT data were initially processed with a 'smooth' 1-D modeling scheme in the fall of 2002 and winter of 2003. These gave a "first cut" at the subsurface electrical resistivity structure. These results are displayed in Appendix B. It became clear that further modeling, in particular 2-dimensional inversion, of lines D, E, F, G, H, I, and X was necessary to fully take advantage of the AMT data. Lines A and C in the southwest were not deemed as important as the northeastern area.

In the summer and fall of 2004, Louise Pellerin of Green Engineering processed the AMT data with modeling codes included in the MT Works Graphical User Interface modeling package (Hoversten, 2001). Pellerin (2004) used the conjugate-gradient inversion algorithm developed by Rodi and Mackie (2001) to analyze the TEAD AMT data. Inverse models were computed for a variety of parameter combinations. The inversion seemed to work best for inversion of apparent resistivity and phase for the TM mode (along the line) starting with a $100 \mathrm{ohm}-\mathrm{m}$ halfspace starting model. Some of inversion results for lines $\mathrm{G}, \mathrm{H}$, and I are shown on figure 9 (taken from fig. 6 in Pellerin [2004]).

The Line $\mathrm{H}$ interpretation (middle section on fig. 9), at about 3,000 ft along the line, shows a large conductive zone at about $750 \mathrm{ft}$ and deeper. The small plus symbols (+) at the top of each section are the original station locations. The noted conductive zone is centered under a gap in the data acquisition stations that is due to the crossing of Highway 112. Note also the conductive zone in the Line I section at about $5,000 \mathrm{ft}$ along the line. This data acquisition gap is also due to crossing Highway 112. The question is whether these conductive zones are "real", that is, actually exist in the subsurface geology or are artifacts of the modeling and inversion algorithms. Some inversion schemes are known to add very conductive or very resistive fictitious zones to a model in order to locally reduce the modeling error.

Geophysicists at the U.S. Geological Survey undertook a "refinement" of the modeling and inversion conducted in Pellerin (2004) in order to address the reality question of the conductive zones in the 2-D inversions and to better delineate the AMT bedrock depth including locations of possible basement and alluvial faults. The refinement consisted of first reinverting the STRATAGEM AMT data with 2-D inversion codes similar to those used by Pellerin (2004) and then performing forward modeling with PW2D (developed by Wannamaker, 1989) on the results to test different geologic hypotheses. The results are presented in Appendix C.

On the figures in Appendix C, a pink line marks the interpreted AMT bedrock surface, and black lines mark faults with ground movement indicated with up and down arrows. The AMT-interpreted depth of the bedrock surface is based on a consideration of the displayed resistivity distribution, borehole geophysical logging information, and the gravity and TEM data and interpretations. In some cases, the displayed resistivity distribution directly indicates the presence of bedrock at a given depth. An example of this interpretation is shown on figure C-2 (Line D North) where wells P-11 and C-11 (along the line around 4,000 ft and 4,500 ft, respectively) intersected bedrock during drilling. The borehole-interpreted bedrock depths are near the top of the shallow resistive zone on figure $\mathrm{C}-2$. In other cases the direct relation of electrically resistive material indicating bedrock does not hold up. A comparison of the modeled resistivity distribution to other borehole lithology logs indicates that some very resistive zones actually are dry unsaturated gravels in the alluvium that are lying on top of electrically resistive bedrock. The 2-D interpretation for Line $\mathrm{H}$ on figure $\mathrm{C}-7$ shows a good example of this. Above the water table, the dry gravels are resistive. Below the water table, they are electrically conductive. Below the saturated gravels lies the resistive bedrock. Directly selecting the top of the high resistivity zones to represent the depth to bedrock will not always work.

Figures C-2 and C-3 are modeling results for the north to south trending Line D. The length of Line D (about 12,000 ft) and a limitation on the number of stations that can be modeled 
at one time forced Line $\mathrm{D}$ to be broken up into two parts - a northern section $(0-7,000 \mathrm{ft})$ and an overlapping southern section $(5,000-12,000 \mathrm{ft})$. The bedrock is somewhat deeper in the north and at the south end of the line. From about 2,500 ft to $7,000 \mathrm{ft}$ the subsurface is very resistive. This is indicative of very competent bedrock. There is a fault around 2,500 ft and another just before Line D crosses Line G, around 4,500 ft.

Line E (fig. C-4) also trends from north to south and crosses both Line $\mathrm{G}$ and Line $\mathrm{H}$. The bedrock is predominantly deep for most of Line E. There appear to be basinbounding faults at either end of Line $\mathrm{E}$ - just before crossing Line $\mathrm{G}$ and then again before Line $\mathrm{E}$ crosses Line $\mathrm{H}$.

The section for Line F (fig. C-5) depicts what appears to be the edge of a large basin. The bedrock is deeper in the north and becomes shallower to the south. En echelon faulting, indicated by the offset pattern of resistive blocks, separates the more conductive basin material from the more resistive basement blocks on the south side of the large subsurface valley.

Line G (fig. C-6) is a west to east trending line in which the bedrock is shallow on the western end and deepens to the east.

Figure C-7 is the new 2-D inversion result for Line $\mathrm{H}$. Note that the Line $\mathrm{H}$ conductive zone noted on figure 9 (Pellerin [2004] results) does indeed exist and actually is much broader than what is shown in the Pellerin results. It appears that Line $\mathrm{H}$ crosses a depression in the basement that the borehole lithology logs indicate is silty and sandy gravels. As discussed above, almost everything above the pink line in that
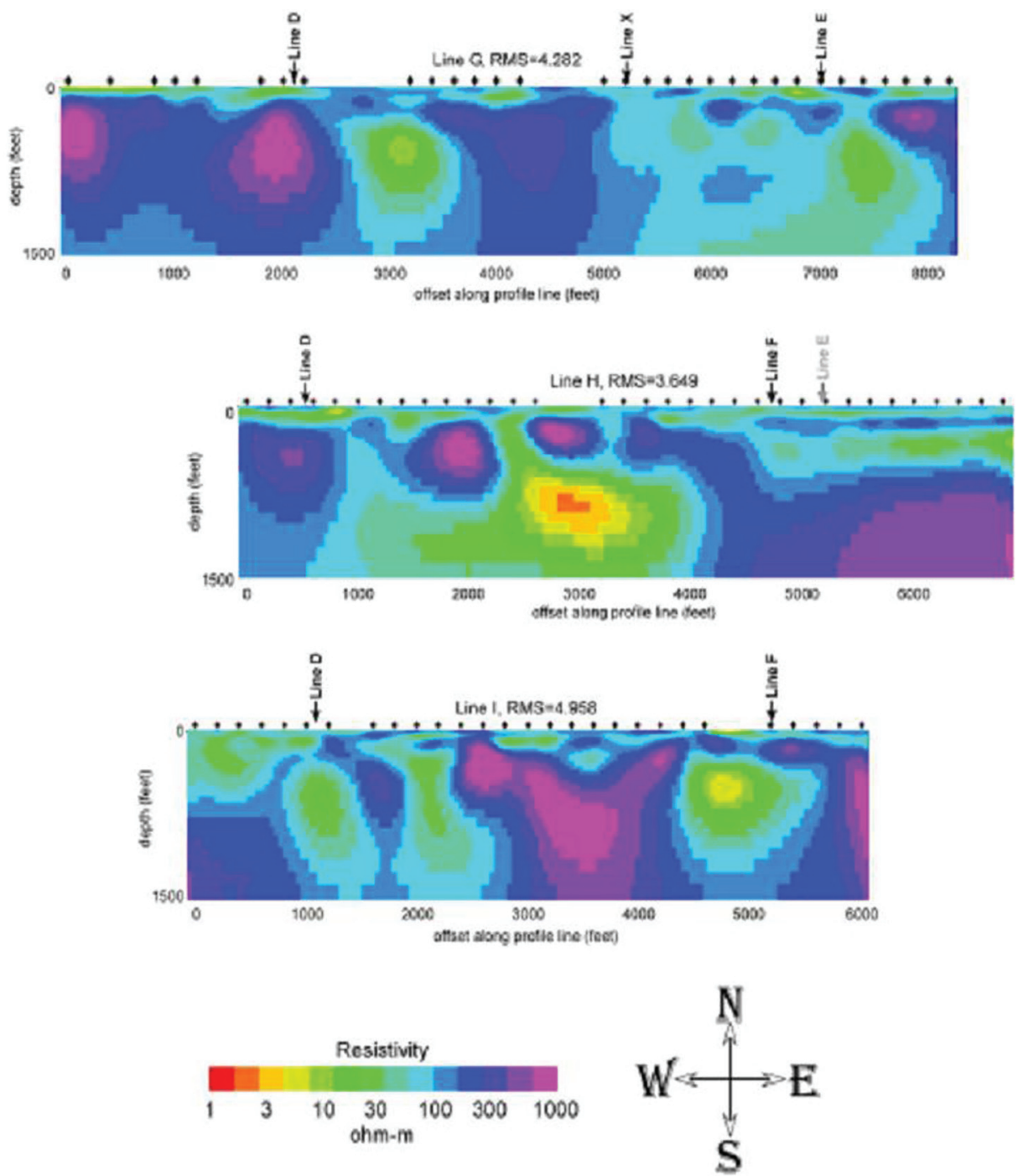

Figure 9. Example of 2-D inversion modeling in Pellerin, 2004 (taken from fig. 6). The plus (+) symbols at the top of each section are station locations. 
area is gravel. What is interesting is that the gravel zone is divided into two sections. The shallower gravels are electrically very resistive $(5,000 \mathrm{ohm}-\mathrm{m})$, and the deeper gravels are conductive $(20 \mathrm{ohm}-\mathrm{m})$. The interpretation is that the whole section is gravel but that the top of the conductive zone is the top of the water table, and the gravel above that is very dry and so very electrically resistive.

Figure C-8 shows the inversion results for Line I. In this case, the AMT inversion and modeling refinement determined that the conductive zone at about 5,000 ft along Line I on figure 9 is not "real". In fact, this zone is electrically, very resistive.

On figure C-9, the refined results for Line $\mathrm{X}$ are presented. Lack of access during the survey caused the large gap area in the middle of the line. The refined interpretation for Line $\mathrm{X}$ puts a fault somewhere in the gap area. It is difficult to determine exactly where this fault should be unless more data are acquired.

Section 3.3 below discusses the pink-line bedrock depths and elevations indicated in the figures in Appendix C.

\subsection{Integration of TEAD Geophysics}

Integration of the various interpretations from the different geophysical methods involves overlaying one interpretation on another and comparing how similar or dissimilar they are to one another. In this section, the different data sets are put together in three configurations. The first is the TEM-, gravity-, and AMT- interpreted depths overlain on the reflection/refraction seismic section (fig. 10). The next data set shows the locations of the AMT-interpreted faults overlain on the gravity bedrock elevation map (fig. 11). The last data set is the AMT-interpreted bedrock map with the faults and orientations inferred (fig. 12).

Table 2 shows the relations between the interpreted depth and elevation of bedrock for the Original TEM, Revised TEM, Gravity, and AMT investigations. As discussed before, the TEM-derived depths were reevaluated because of incompatibilities with the borehole lithology logs and the interpreted gravity bedrock elevations shown on figure 11 .

Some TEM depths changed and some depths did not change. When comparing the TEM Rev. depths versus the TEM Org. depths (Table 2), the elevations decreased for stations 51-56 and increased for stations 13-16. Stations 61-66 became slightly higher in elevation as stations 31-42. The TEM-Rev. depths are in general agreement with the gravity although some are slightly deeper and some are shallower. is difference primarily is a function of limitations of the 1-D modeling used to interpret the TEM data. The AMT depths are taken off of the contoured AMT bedrock elevation map on figure 12 at the locations of the TEM stations. As with the TEM data some of the AMT-derived depths are in close agreement with the gravity. Others are shallower, and some are deeper. There are no AMT depths/elevations for TEM stations 62 and 63 because no AMT data were collected in that area with which a comparison could be made.

\subsection{Seismic Base with Gravity, TEM, AMT, and Borehole}

The seismic reflection results shown on figure 3 are redisplayed on figure 10 (and pl. 2) but with depths interpreted from the gravity analysis, TEM 1-D inversion, and the AMT 2-D inversion where the seismic line crosses lines $\mathrm{H}, \mathrm{D}$, and I. There are several interesting features to note. The first is the good correlation of the bedrock depth estimates between the gravity, TEM, and seismic from $0 \mathrm{~m}$ to about $1,100 \mathrm{~m}$. Secondly, TEM stations 13 and 14 had seemed anomalously deep in relation to borehole B-9 near $500 \mathrm{~m}$. It turns out that TEM stations 13 and 14 are on either side of the bedrock high. The revised TEM depths correspond well with the gravity bedrock depths and the interpreted seismic bedrock depth in that area. AMT depths on lines H, D, and I also correspond well.

Third, two large faults appear in the seismic section around $1,200 \mathrm{~m}$ and $1,600 \mathrm{~m}$. At these locations the TEM stations (17 and 54 at 1,200 m and station 18 near 1,600 m) produced inconsistent results. This likely is due to varying properties in the two fault zones. The zones may be electrically more conductive and/or unusually dense as compared to the surrounding material. It is hard to determine from the seismic data alone if there are faults around $1,800 \mathrm{~m}$, around $2,100 \mathrm{~m}$, and possibly $2,300 \mathrm{~m}$. The next section addresses the possible existence of these using the gravity interpretation as the basis of integration.

\subsection{Gravity Base with TEM, AMT, and Borehole}

Figure 11 and plate 3 show the results of integrating bedrock interpretations based on the gravity survey, TEM, and the 2-D AMT inversion and modeling. The results of the separate interpretations are shown on figure 8, table 2, and in Appendix C. The seismic traverse line is indicated as a red northwest to southeast trending line. Time-domain stations are shown as red boxes with associated station numbers. The short dashed blue lines mark the locations of the faults indicated by the AMT data. The estimated azimuths of the inferred faults are based on examination of the underlying gravity bedrock structure and the major topographic trends. It should be noted that some of these major topographic trends might be more related to bedrock competency and differential erosion than to faults.

The AMT fault locations, the seismic data, and the gravity-derived interpretation of the bedrock surface provide strong evidence for the bedrock highs being fault controlled. The gravity data have provided the basic structure of the area and indications that the bedrock highs probably are fault controlled. The addition of the AMT data has provided more detailed information on the probable locations of the actual faults that could be controlling ground-water flow.

The integrated gravity results on figure 11 help to confirm the existence of several faults at the southern end of the seismic line. There are three AMT-inferred faults at the south end 
Table 2. TEM site locations and original and reinterpreted bedrock depths. Northwest Geophysics gravity interpretation bedrock depths and audiomagnetotelluric depths are also included for comparison

\begin{tabular}{|c|c|c|c|c|c|c|c|c|c|c|c|}
\hline Site & $\begin{array}{c}\text { E ft (N83, } \\
\text { Utah Cent } \\
4302) \\
\end{array}$ & $\begin{array}{c}\mathrm{N} \mathrm{ft}(\mathrm{N} 83, \\
\text { Utah Cent } \\
4302) \\
\end{array}$ & $\begin{array}{l}\text { Surface } \\
\text { Elev (ft) }\end{array}$ & $\begin{array}{l}\text { TEM Org. } \\
\text { Bedrock } \\
\text { Depth (ft) } \\
\end{array}$ & $\begin{array}{c}\text { TEM Org. } \\
\text { Bedrock } \\
\text { Elev }(\mathrm{ft}) \\
\end{array}$ & $\begin{array}{l}\text { TEM Rev. } \\
\text { Bedrock } \\
\text { Depth }(\mathrm{ft}) \\
\end{array}$ & $\begin{array}{l}\text { TEM Rev. } \\
\text { Bedrock } \\
\text { Elev }(\mathrm{ft}) \\
\end{array}$ & $\begin{array}{c}\text { NWG Gravity } \\
\text { Bedrock } \\
\text { Depth (ft) } \\
\end{array}$ & $\begin{array}{c}\text { NWG Gravity } \\
\text { Bedrock Elev } \\
\text { Map (ft) }\end{array}$ & $\begin{array}{c}\text { AMT } \\
\text { Bedrock } \\
\text { Depth (ft) } \\
\end{array}$ & $\begin{array}{c}\text { AMT } \\
\text { Bedrock } \\
\text { Elev }(\mathrm{ft}) \\
\end{array}$ \\
\hline 51 & 1402329 & 7368434 & 4718 & -161 & 4557 & -236 & 4482 & -248 & 4470 & -278 & 4440 \\
\hline 53 & 1402985 & 7368537 & 4718 & -167 & 4551 & -276 & 4442 & -298 & 4420 & -313 & 4405 \\
\hline 54 & 1403641 & 7368639 & 4744 & -354 & 4390 & -397 & 4347 & -404 & 4340 & -379 & 4365 \\
\hline 55 & 1404231 & 7368741 & 4738 & -374 & 4364 & -554 & 4184 & -528 & 4210 & -458 & 4280 \\
\hline 56 & 1404854 & 7368843 & 4734 & -374 & 4360 & -554 & 4180 & -614 & 4120 & -576 & 4158 \\
\hline 57 & 1405542 & 7368945 & 4741 & -679 & 4062 & -679 & 4062 & -701 & 4040 & -681 & 4060 \\
\hline 27 & 1401884 & 7365938 & 4725 & -282 & 4443 & -282 & 4443 & -305 & 4420 & -225 & 4500 \\
\hline 11 & 1402044 & 7372305 & 4643 & -177 & 4466 & -177 & 4466 & -163 & 4480 & -201 & 4442 \\
\hline 12 & 1402342 & 7371782 & 4659 & -164 & 4495 & -164 & 4495 & -134 & 4525 & -217 & 4442 \\
\hline 13 & 1402641 & 7371193 & 4692 & -348 & 4344 & -164 & 4528 & -112 & 4580 & -252 & 4440 \\
\hline 14 & 1402924 & 7370571 & 4702 & -354 & 4348 & -164 & 4538 & -162 & 4540 & -257 & 4445 \\
\hline 15 & 1403206 & 7370080 & 4715 & -325 & 4390 & -239 & 4476 & -245 & 4470 & -275 & 4440 \\
\hline 16 & 1403570 & 7369525 & 4734 & -364 & 4370 & -246 & 4488 & -339 & 4395 & -329 & 4405 \\
\hline 17 & 1403869 & 7368870 & 4757 & -384 & 4373 & -384 & 4373 & -447 & 4310 & -417 & 4340 \\
\hline 18 & 1404233 & 7368281 & 4761 & -449 & 4312 & -449 & 4312 & -546 & 4215 & -486 & 4275 \\
\hline 21 & 1402993 & 7372770 & 4633 & -285 & 4348 & -285 & 4348 & -233 & 4400 & -253 & 4380 \\
\hline 22 & 1403292 & 7372181 & 4636 & -315 & 4321 & -315 & 4321 & -236 & 4400 & -270 & 4366 \\
\hline 23 & 1403558 & 7371625 & 4675 & -325 & 4350 & -325 & 4350 & -300 & 4375 & -320 & 4355 \\
\hline 24 & 1403823 & 7371101 & 4685 & -364 & 4321 & -364 & 4321 & -345 & 4340 & -360 & 4325 \\
\hline 25 & 1404089 & 7370545 & 4695 & -387 & 4308 & -387 & 4308 & -395 & 4300 & -395 & 4300 \\
\hline 26 & 1404388 & 7369956 & 4708 & -561 & 4147 & -561 & 4147 & -503 & 4205 & -468 & 4240 \\
\hline 61 & 1406716 & 7370166 & 4718 & -945 & 3773 & -853 & 3865 & -838 & 3880 & -783 & 3935 \\
\hline 62 & 1411763 & 7371443 & 4731 & -984 & 3747 & -886 & 3845 & -831 & 3900 & NA & NA \\
\hline 63 & 1411240 & 7371062 & 4744 & -984 & 3760 & -807 & 3937 & -794 & 3950 & NA & NA \\
\hline 64 & 1409764 & 7370939 & 4754 & -984 & 3770 & -761 & 3993 & -754 & 4000 & -684 & 4070 \\
\hline 65 & 1409175 & 7370640 & 4757 & -984 & 3773 & -705 & 4052 & -697 & 4060 & -689 & 4068 \\
\hline 66 & 1408587 & 7370243 & 4764 & -984 & 3780 & -682 & 4082 & -664 & 4100 & -689 & 4075 \\
\hline 31 & 1409334 & 7371527 & 4728 & -984 & 3744 & -803 & 3925 & -790 & 3938 & -706 & 4022 \\
\hline 32 & 1408674 & 7372114 & 4741 & -984 & 3757 & -833 & 3908 & -831 & 3910 & -751 & 3990 \\
\hline 58 & 1405595 & 7368273 & 4728 & -663 & 4065 & -663 & 4065 & -608 & 4120 & -528 & 4200 \\
\hline 33 & 1408347 & 7374737 & 4656 & -984 & 3672 & -722 & 3934 & -664 & 3992 & -586 & 4070 \\
\hline 34 & 1408952 & 7375069 & 4656 & -984 & 3672 & -738 & 3918 & -681 & 3975 & -586 & 4070 \\
\hline 35 & 1407996 & 7375786 & 4633 & -984 & 3649 & -570 & 4063 & -573 & 4060 & -520 & 4113 \\
\hline 36 & 1409679 & 7374319 & 4643 & -984 & 3659 & -715 & 3928 & -743 & 3900 & -603 & 4040 \\
\hline 41 & 1408076 & 7373358 & 4682 & -984 & 3698 & -640 & 4042 & -737 & 3945 & -627 & 4055 \\
\hline 42 & 1409772 & 7372383 & 4728 & -984 & 3744 & -646 & 4082 & -868 & 3860 & -718 & 4010 \\
\hline
\end{tabular}



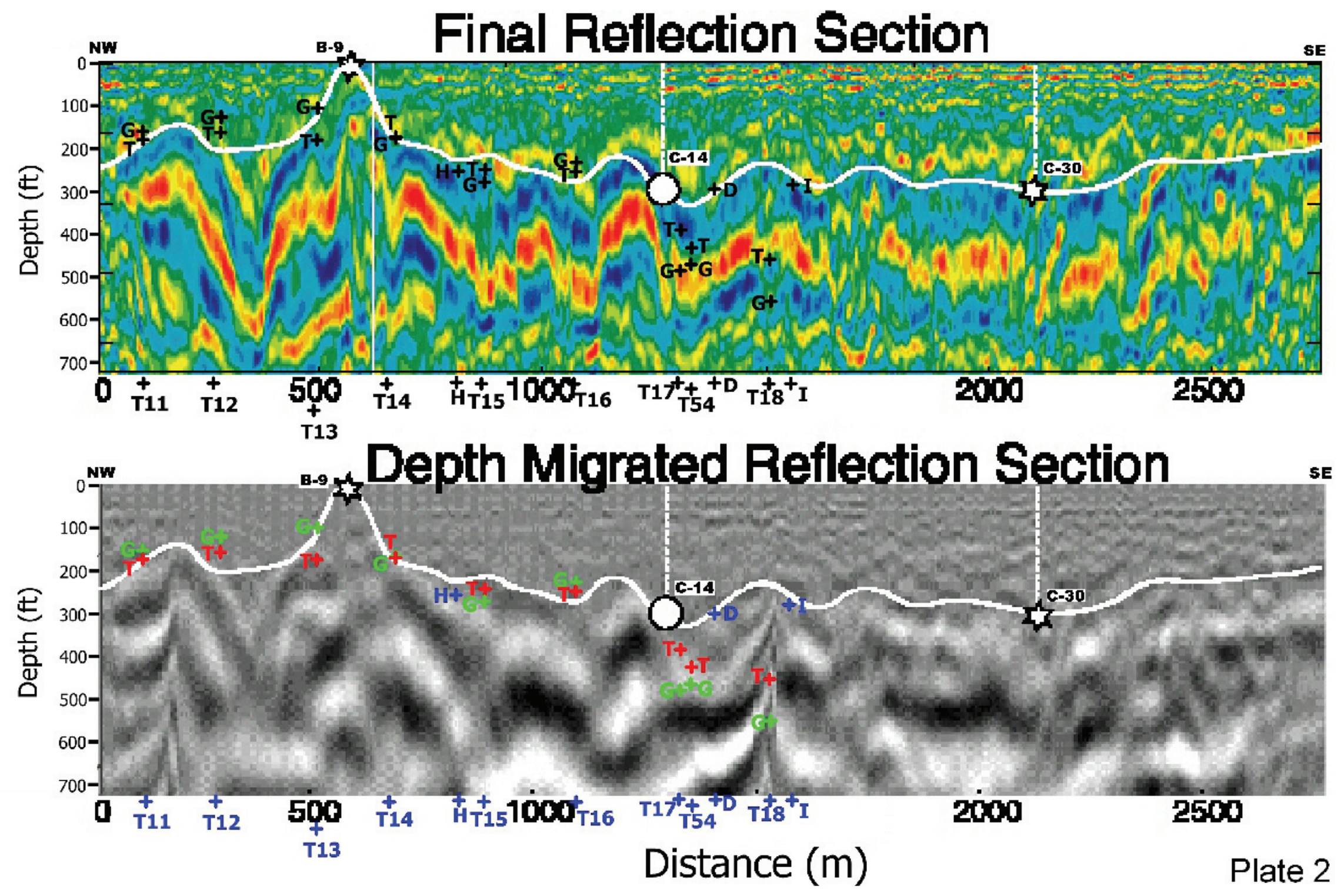

Figure 10 (pl. 2). Seismic reflection results with interpreted bedrock depths from gravity (green $\mathrm{G}+$ ), TEM (red $T+$ ), and AMT line crossings (blue $\mathrm{H}_{+}, \mathrm{D}_{+}$, and $\mathrm{I+}$ ). Note that the vertical scale is in feet, and the horizontal scale is in meters. 
of Line D (fig. C-3) that, if extended, would cross the reflection/refraction seismic survey traverse just northwest of well C-30. These may be the same faults observed on the southern end of the seismic section on figure 10 and plate 2. However, there is not enough site coverage to confidently continue the faults across the area.

\subsection{AMT, Gravity, TEM, Borehole}

Estimating the bedrock depth solely from the AMT data generally resulted in much shallower bedrock elevations than the gravity, TEM, or drilling information would support. Some of the AMT-derived bedrock depths are deeper in the western portion of the site than are suggested by the other geophysical techniques. Usually, in geophysical ground-water exploration, a large conductivity contrast exists between porous overburden sediments and dense, competent basement units. The interpreter would just draw a line between the electrically conductive material and the electrically resistive material and call that the bedrock surface. However, in several areas of TEAD, the dry gravels that overlie the bedrock are just as electrically resistive in the AMT sections as the competent bedrock limestone and sandstone. This is well illustrated on the figures in Appendix C. For example, at the southern end of Line F on figure $\mathrm{C}-5$, the interpreted depth to bedrock is beneath the $1,000 \mathrm{ohm}-\mathrm{m}$ near surface resistive zone. Another example is the section for Line I (fig. C-8). None of the wells near Line I intersected bedrock during drilling. However, while well C-18 was drilled into the top of a resistive zone (probably dry gravels), wells P-7 and C-38 bottomed out in slightly less resistive materials at greater depths on either side of a shallower, more resistive zone.

There is some, but not a complete, correlation between electrical resistivity and the depth to basement. This observation is based on the inclusion on the figures in Appendix $\mathrm{C}$ of the TEM 1-D estimates of bedrock depth (marked in red) and the boreholes approximately located along the AMT data measurement lines. Wells that intersected bedrock during drilling are marked at depth as completely filled white circles. Wells that did not intersect bedrock are marked with an inverted triangle in a white (or black) circle.

The borehole drilling information is taken as ground truth for bedrock depth. In areas where some wells were drilled that did not intersect bedrock, the 2-D inversions show no resistivity difference between the shallower gravels and deeper basement limestone units. For instance, on figure $\mathrm{C}-8$, the inversion results for Line I, three wells P-7, C-38, and C-18 are marked as not having intersected bedrock while drilling. Well C-18 appears to have been drilled to a depth just above the bedrock surface while P7 and C-38 were drilled deep into the resistive material.

Using only the tops of the more resistive zones would incorrectly demarcate the bedrock surface.

Given the apparent discrepancy and lack of sensitivity in some areas of the AMT results to the true bedrock surface, the pink lines on the figures in Appendix C were drawn after consideration of the AMT data, the gravity- and TEM-indicated depths, as well as the available borehole lithology and electrical well-log information.

Once each AMT inversion section was complete, the interpreted bedrock depths and elevations were digitized, and an AMT-based bedrock map was produced. This map is just an interpolation across all the interpreted bedrock depths from each section. While borehole bedrock depth information was not used directly, it was used to help calibrate the interpreted AMT bedrock depths. This is presented on figure 12 and plate 4. While it is not surprising that this map is somewhat similar to the gravity-based bedrock map (fig. 11), there are still significant differences. While the basic features are the same, some of the detailed features of the elevation contours are different. This is to be expected since the AMT survey technique is more sensitive to lateral changes in geology than potential field techniques like gravity or magnetics. These differences are most notable along AMT lines E and F (fig. C-4 and C-5) where the contours show more definition from the AMT-inferred fault offsets than is shown on figure 11 in the same areas.

The locations of the faults (marked in blue) on figure 12 are based on the AMT inversion modeling results. However, the estimated orientations of the faults are derived from the gravity bedrock map (fig. 11) which shows more of the regional trends than those on figure 12. The correlation of the gravity-oriented faults with the resistivity data is quite good. However, as with the gravity-interpreted bedrock map, only some of the faults can be connected and continued across survey lines. This is an issue of site coverage by the geophysical surveys.

\subsection{Discussion and Conclusions}

Many wells have been drilled, and several geophysical investigations have been conducted to determine ground-water flow and the depth to bedrock in the vicinity of the Tooele Army Depot. The integration of these different geophysical surveys became imperative when, although each survey was performed and interpreted competently, the individual results proved to be ambiguous. Reexamining, correlating, and finally integrating the different geophysical data sets resulted in a more consistent and comprehensive interpretation of the region that was surveyed. However, the interpretation also resulted in identification of several data gaps between the survey lines. These areal data gaps contain information that is necessary to fully characterize the detailed structure surrounding the bedrock highs that could be affecting ground-water flow. Thus, lack of full site coverage is preventing continuity of the geophysical interpretation of faulted blocks between the different lines and stations. An airborne electromagnetic and magnetic survey could provide this continuity and would result in a more comprehensive hydrological interpretation of the Tooele Army Depot area. 


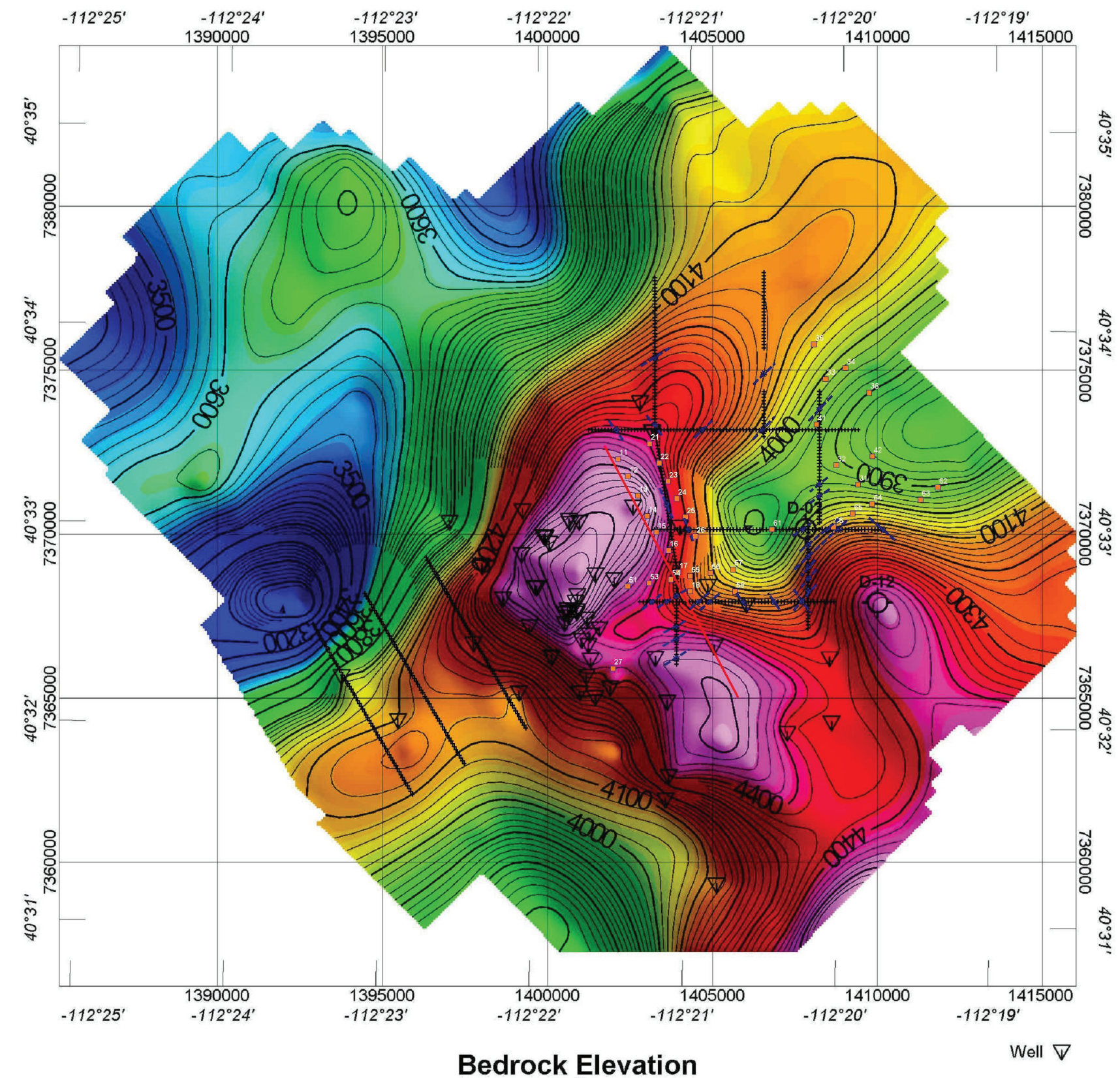

Bedrock Elevation

Well $\nabla$
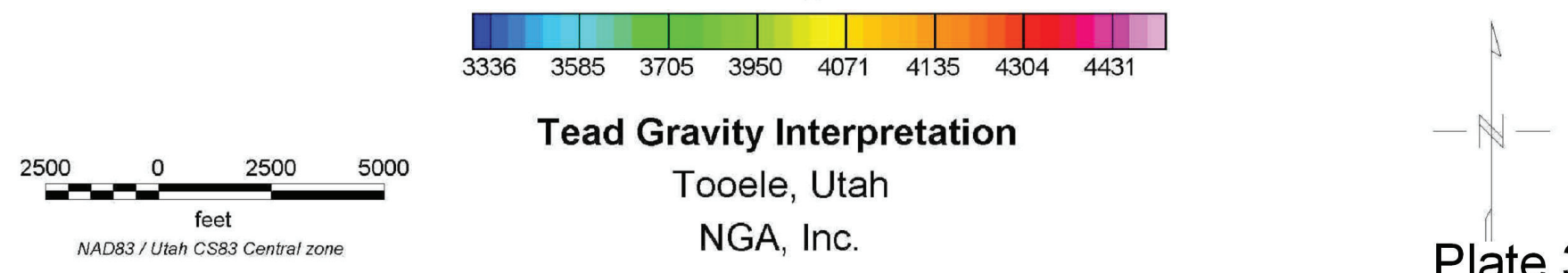

Plate 3

Figure 11 (pl. 3). Interpreted gravity bedrock elevation map with seismic line indicated in red, TEM stations indicated as small red boxes with station numbers (more legible on the attached Plate 3), and faults derived from AMT data interpretation marked as blue dashed lines with estimated orientation indicated. 

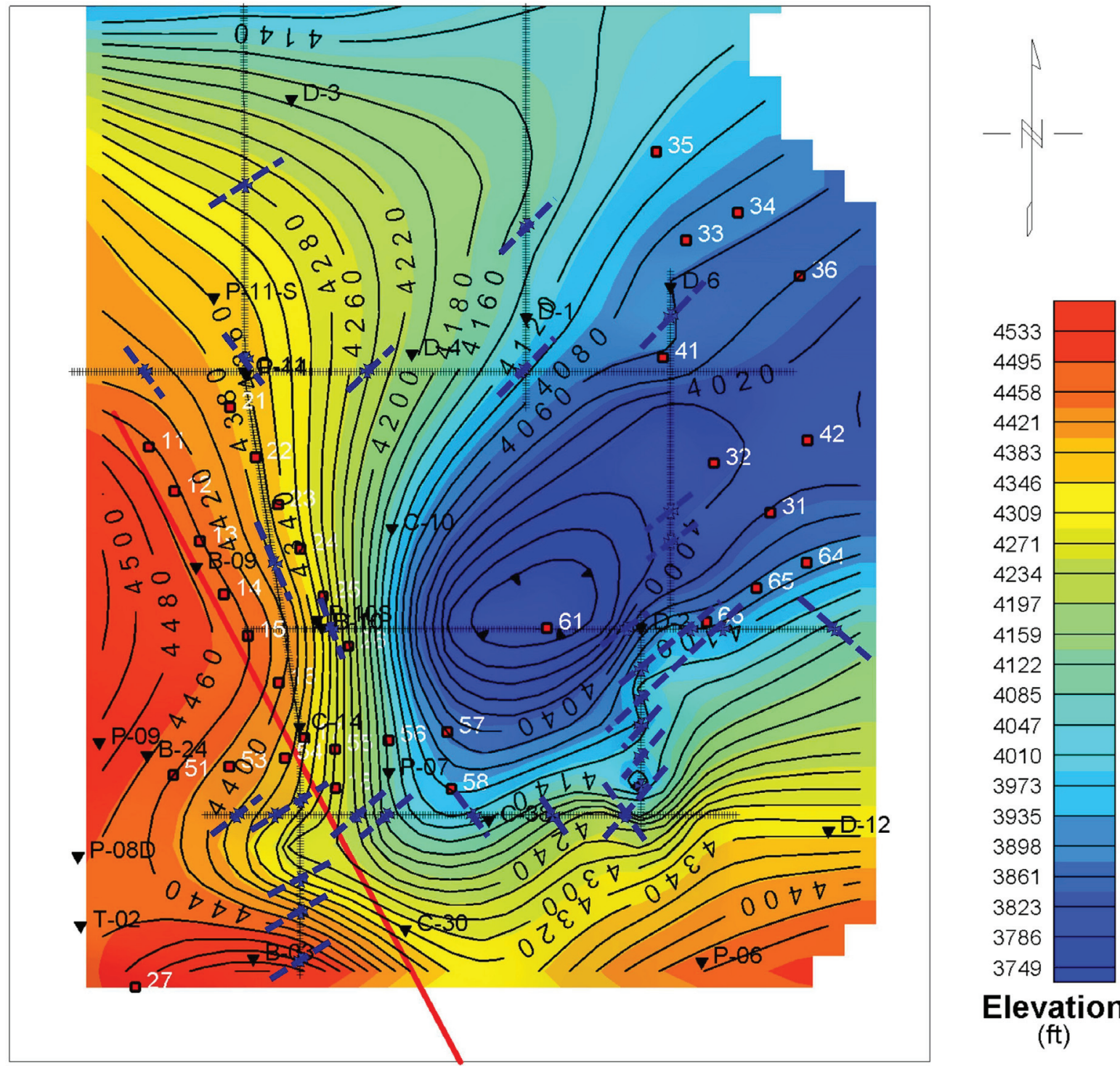

Elevation

(ft)

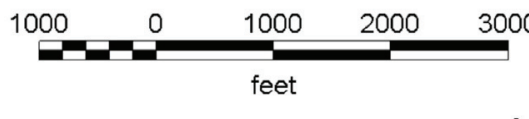

TEAD AMT Bedrock Elevation Map

Seismic Line (red), TEM Locations (red box)

+ AMT Data, Faults (blue dashed) $20 \mathrm{ft}$ Contour Interval

Plate 4

Figure 12. (pl. 4). AMT-derived interpreted bedrock elevation map. Red boxes signify TEM stations. AMT lines marked by plus symbols $(+)$. Seismic traverse marked in red. Short blue dashed lines are faults inferred by AMT modeling and oriented based on gravity bedrock elevation map on figure 11 (pl. 3). 


\subsection{References}

Burger, H.R., 1992, Exploration Geophysics of the Shallow Subsurface: Englewood Cliffs, New Jersey: Prentice Hall.

Hoversten, G.M., 2001, MT Works Graphical User Interface modeling package: Lawrence Berkeley National Laboratory, 2001.

Keller, G.V., 1987, Rock and mineral properties, in Nabighian, M.N., ed., Electromagnetic methods in applied geophysics theory: Tulsa, Oklahoma, Society of Exploration Geophysicists, v. 1, p. 13-51.

Keller, G.V., 1989, Electrical properties, in Carmichael, R.S., ed., Practical handbook of physical properties of rocks and minerals: Boca Raton, Florida, CRC Press, p. 359-427.

Kittner, Anthony, 2003, Draft report: Gravity investigation, Tooele Army Depot, Tooele, Utah: U. S. Army Corps of Engineers, Sacramento District.

Palacky, G.J., 1987, Resistivity characteristics of geologic targets, in Nabighian, M.N., ed., Electromagnetic methods in applied geophysics theory: Tulsa, Oklahoma, Society of Exploration Geophysicists, v. 1, p. 53-129.

Pellerin, Louise, 2004, Final Report: Two-dimensional modeling of the Tooele Army Depot Stratagem AMT data: Green Engineering, Project No. 18600151.03000, 11 p.
Rodi, W. and Mackie, R.L., 2001, Nonlinear conjugate gradients algorithm for 2D magnetotelluric inversion: Geophysics, vol. 66, p. 174-187.

Sheley, David and Yu, Jianhua, 2001, Bedrock delineation by a seismic reflection and refraction survey at Tooele Army Depot, Utah: Prepared for U. S. Army Corps of Engineers, Sacramento District.

Sternberg, B.K., Henley, M.L., and Kay, J.T., 2000, Final Report: Geophysical Research at the Tooele Army Depot: Laboratory for Advanced Subsurface Imaging (LASI), Dept. of Mining and Geological Engineering, University of Arizona, Tucson, Ariz.

Stokes, W.L., 1988, Geology of Utah: Utah Museum of Natural History.

Wannamaker, P.E., 1989, PW2DIS User Documentation - Finite element program for solution of magnetotelluric responses and sensitivities for two-dimensional earth resistivity structure: University of Utah Research Institute, ESL-89042-TR.

Vozoff, Keeva, 1991, The magnetotelluric method, in Nabighian, M.N., Electromagnetic Methods in applied geophysics: Tulsa, Okla., Society of Exploration Geophysicists, v. 2, pt. B, p. 641-711.

Zhdanov, Michael, Golubev, Nikolay, and Pavlov, Dmitriy, 2003, Interpretation of 2002 Gravity Survey in the Area of Tooele Army Depot: University of Utah, Department of Geology and Geophysics, Salt Lake City, Utah. 


\section{APPENDIX A: NGA Gravity Interpretation Cross-Sections}

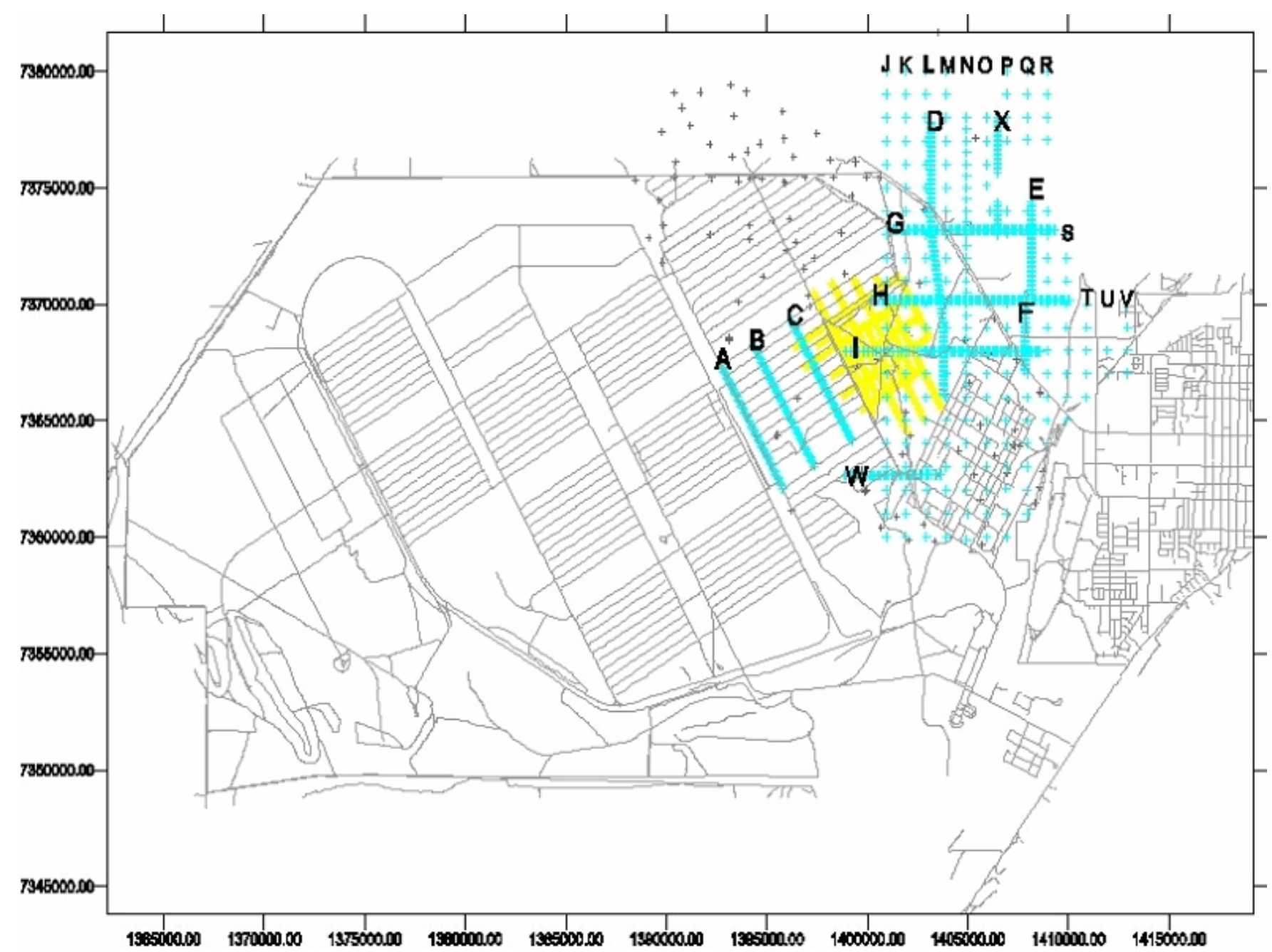

Figure A-1. Index map of locations of gravity interpretation cross-sections. 


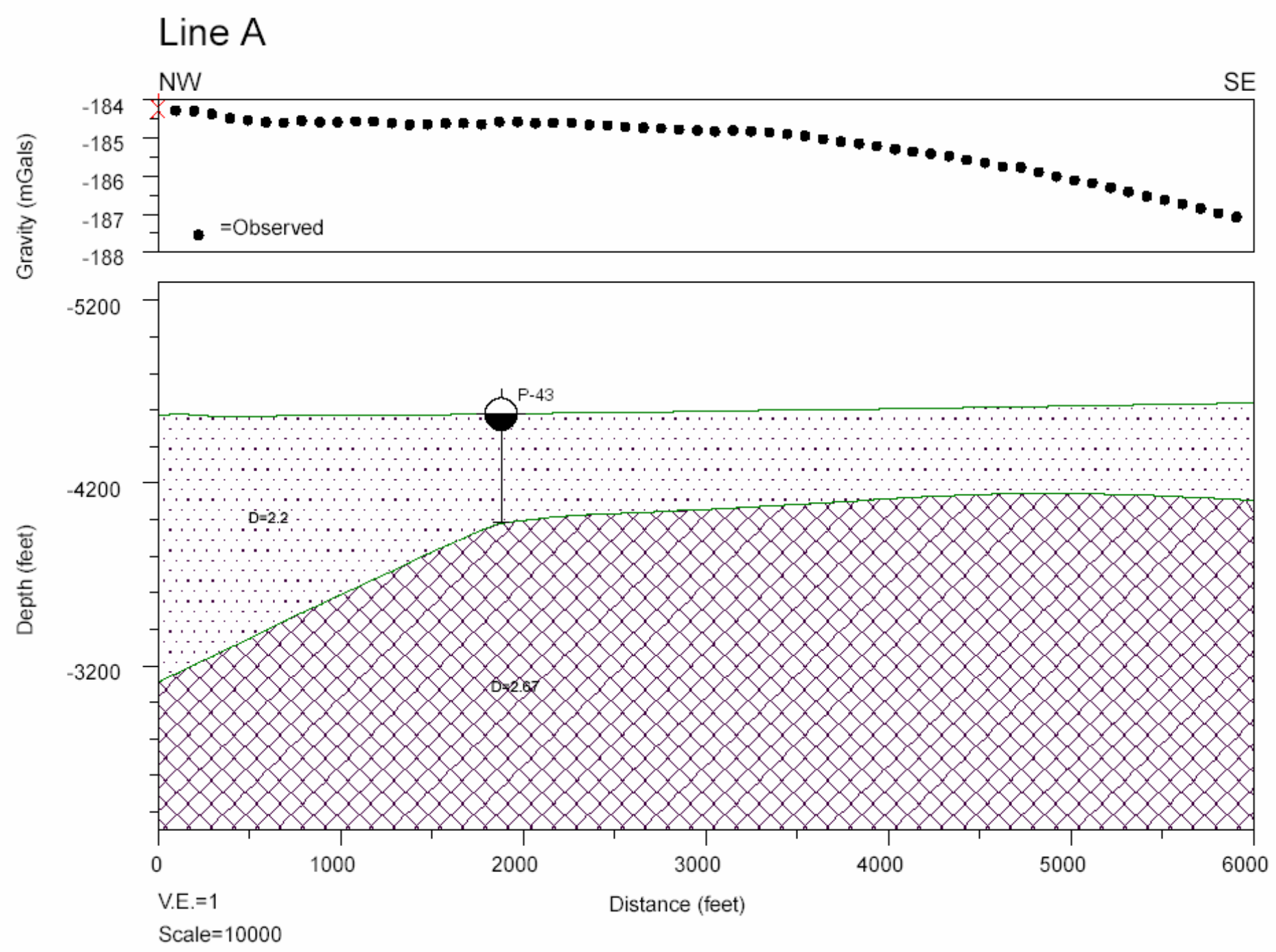

Figure A-2. Gravity interpretation along 2003 Line A. 


\section{Line B}
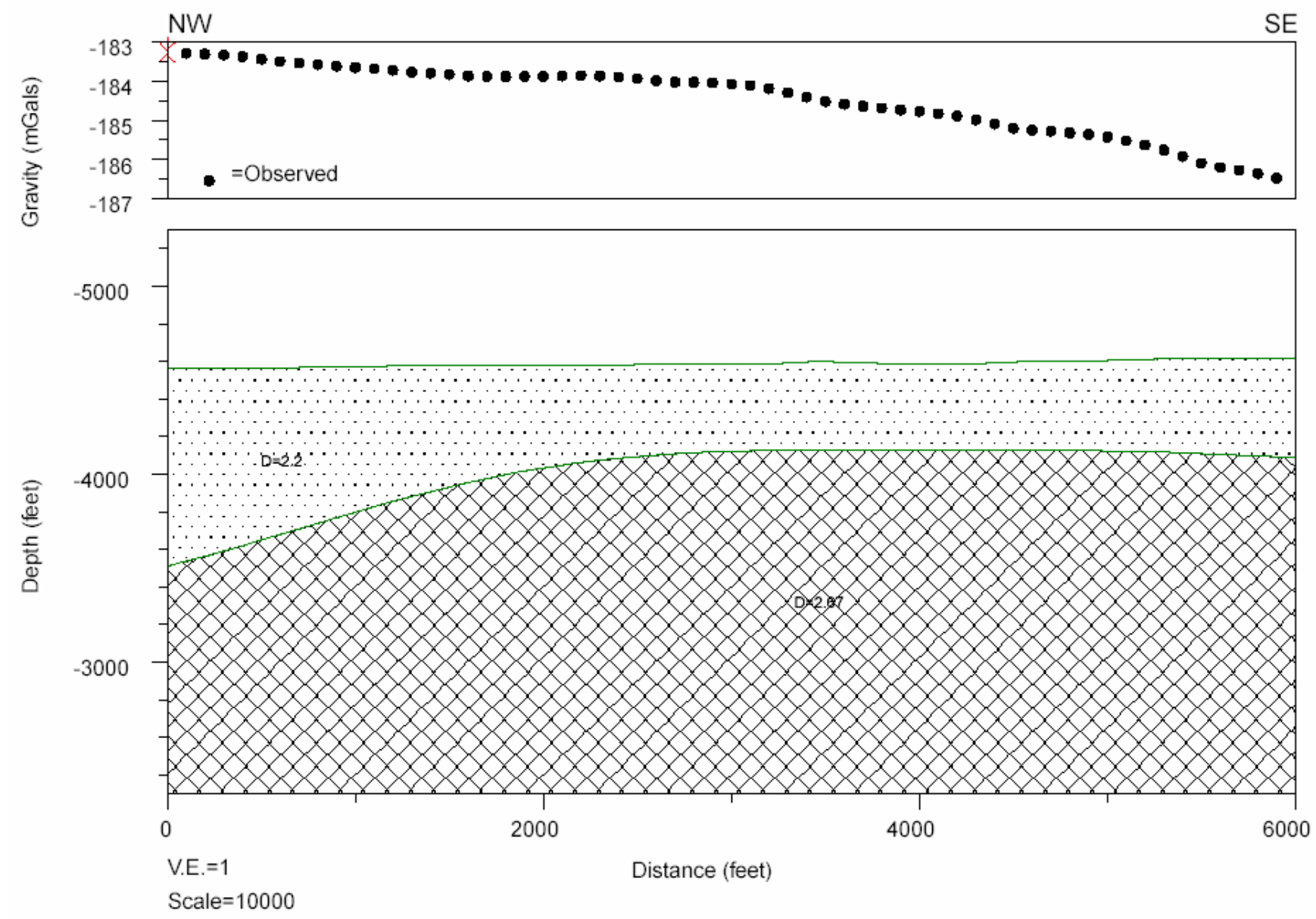

Figure A-3. Gravity interpretation along 2003 Line B 


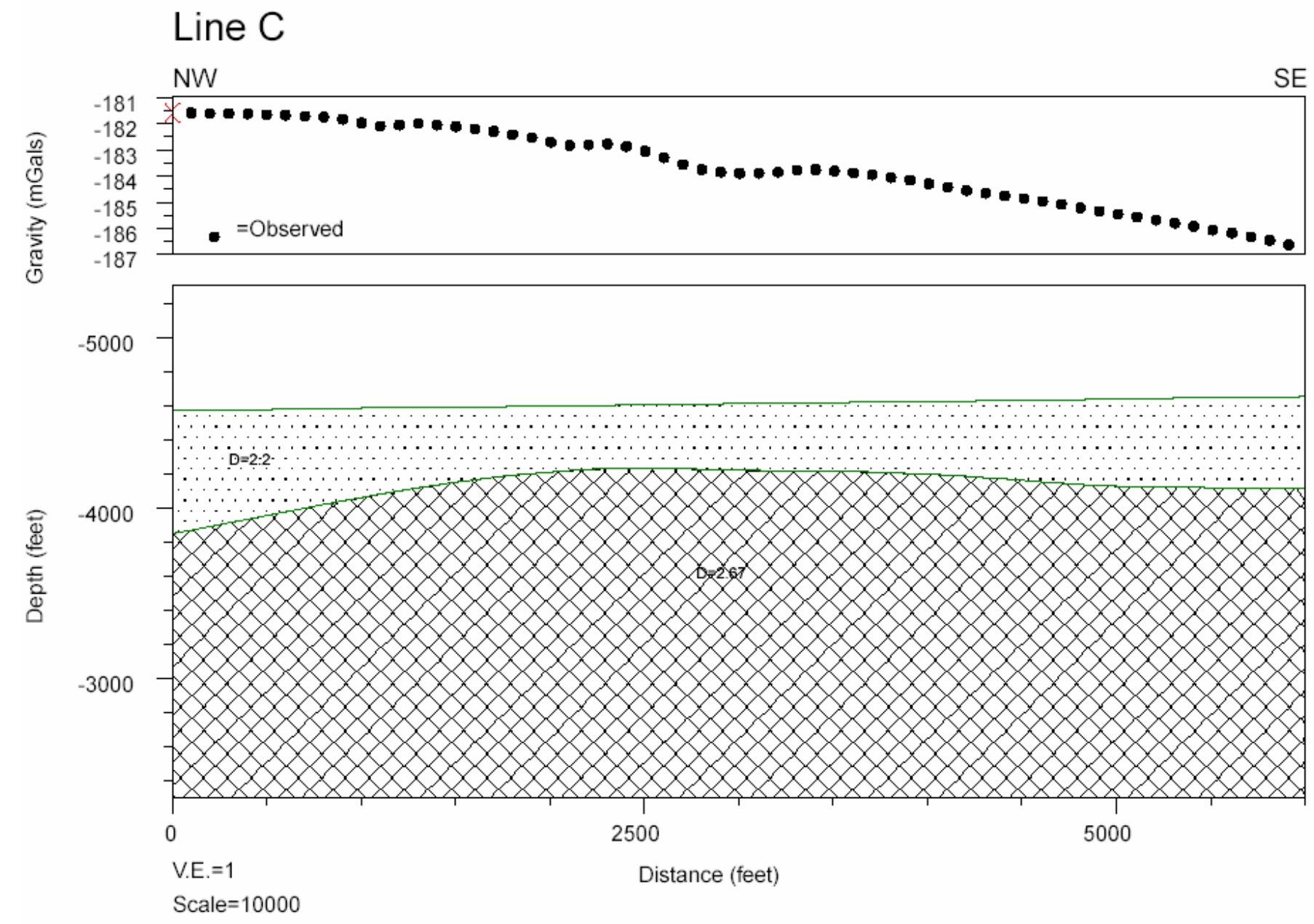

Figure A-4. Gravity interpretation along 2003 Line C. 


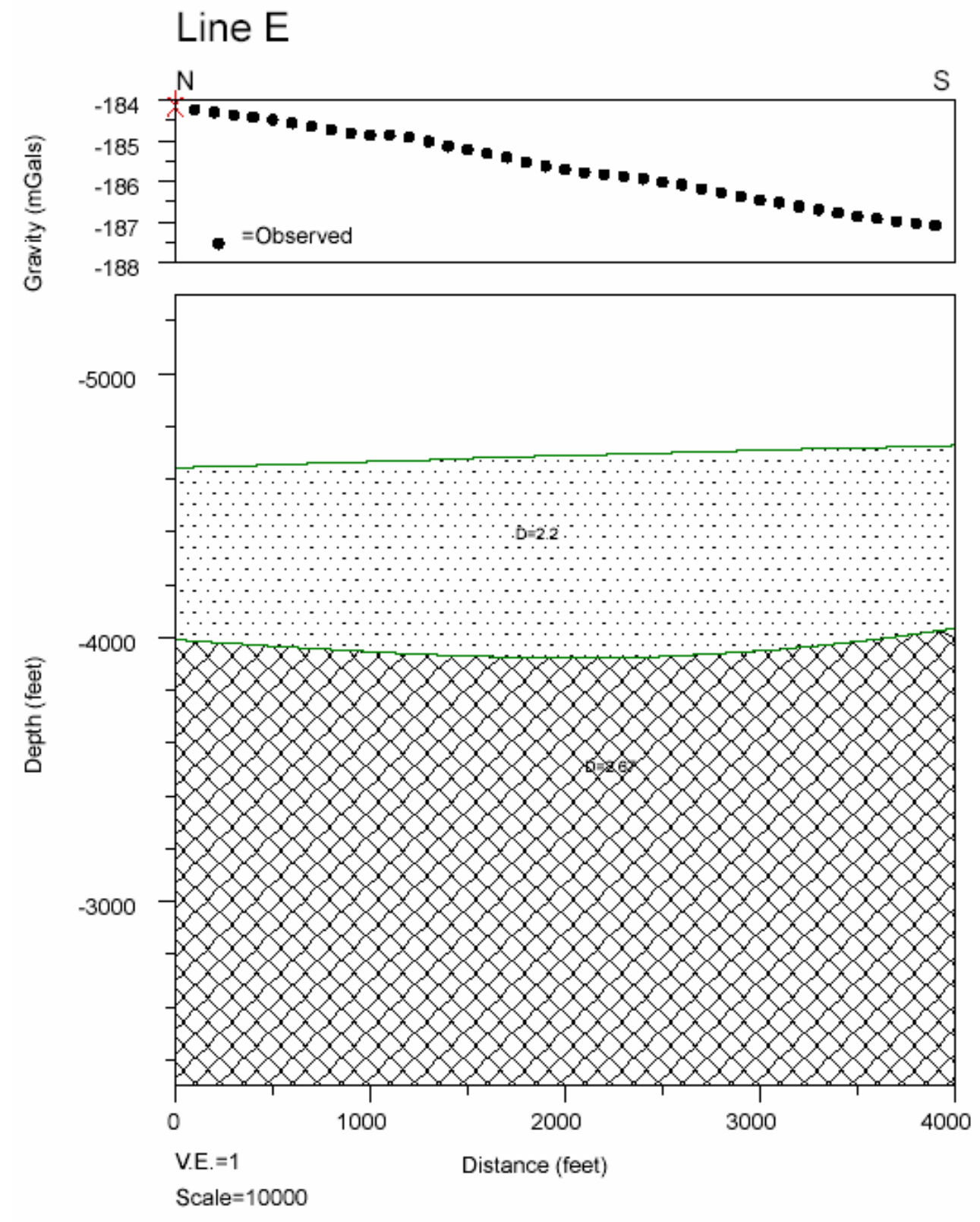

Figure A-5. Gravity interpretation along 2003 Line E. 


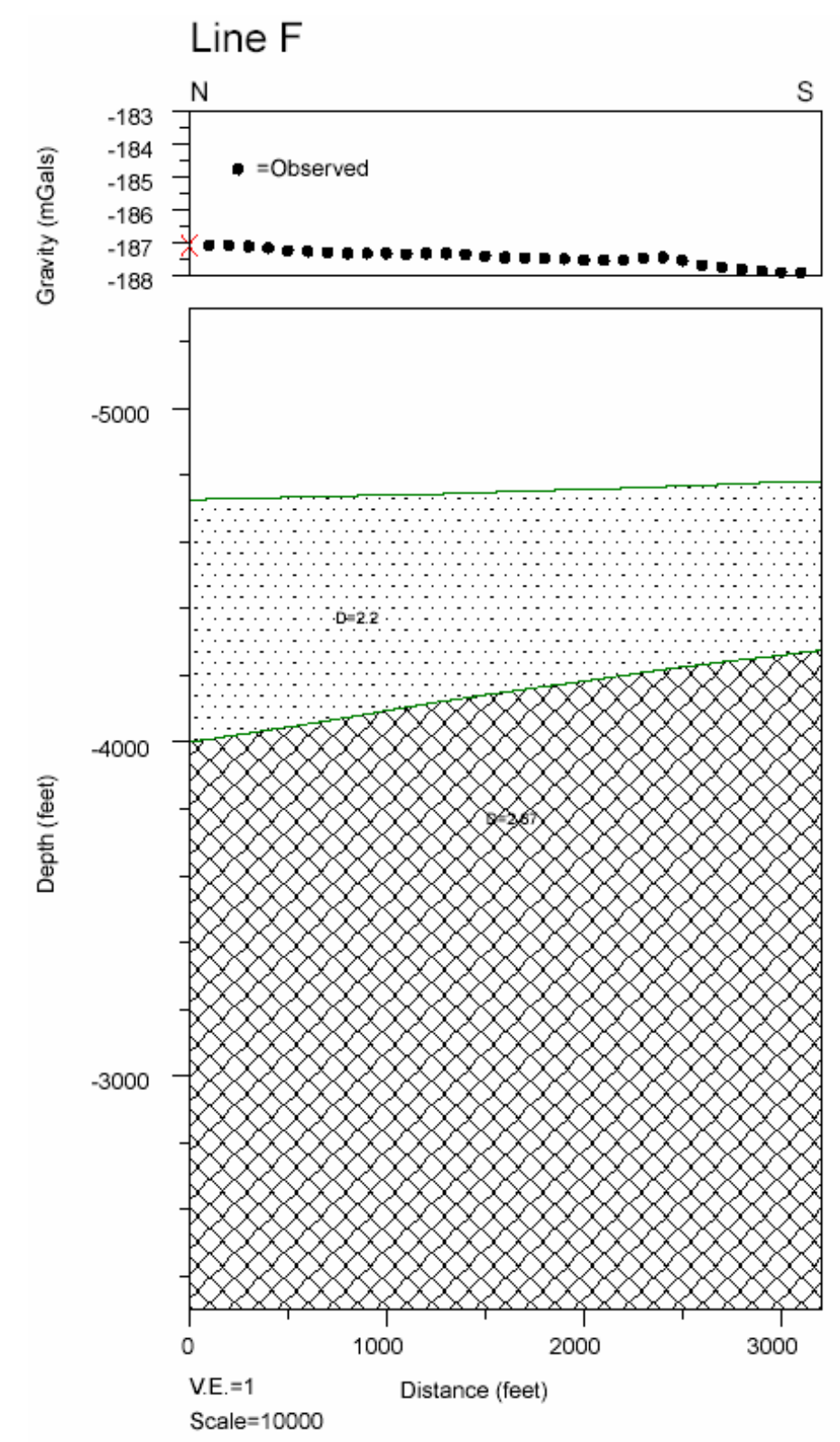

Figure A-6. Gravity interpretation along 2003 Line F. 


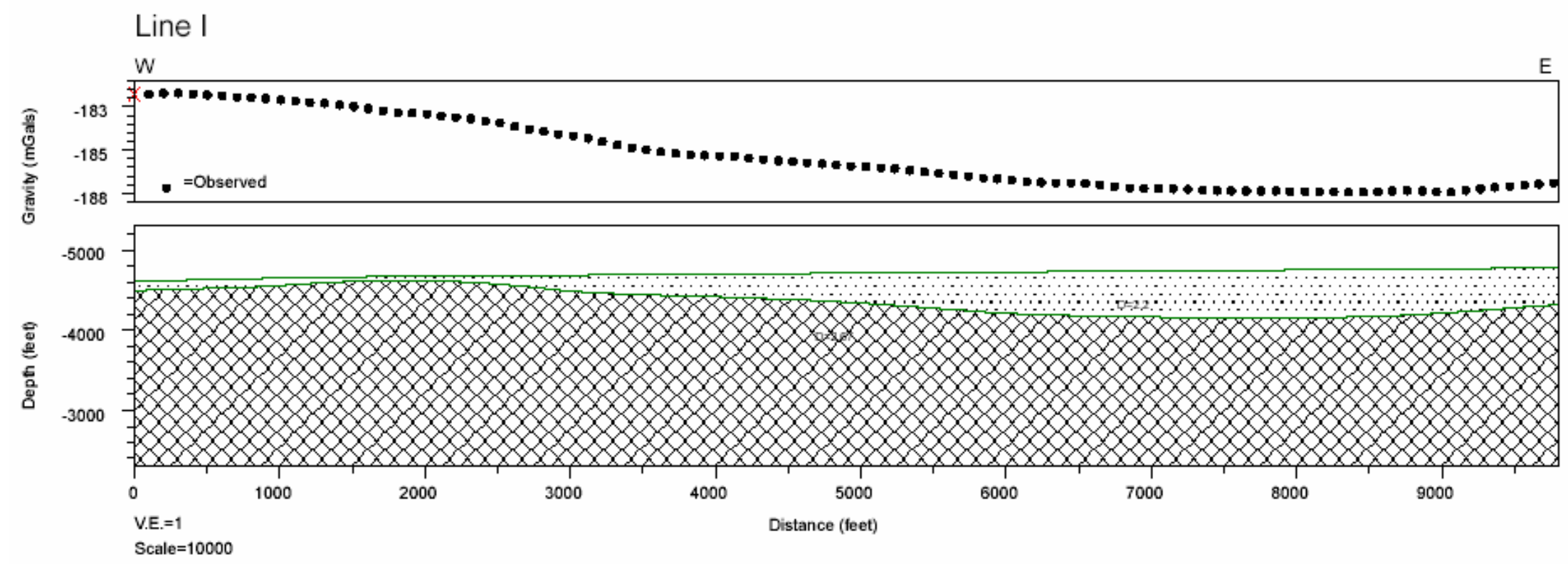

Figure A-7. Gravity interpretation along 2003 Line I. 


\section{APPENDIX B: 1-D AMT Modeling and Interpretation}

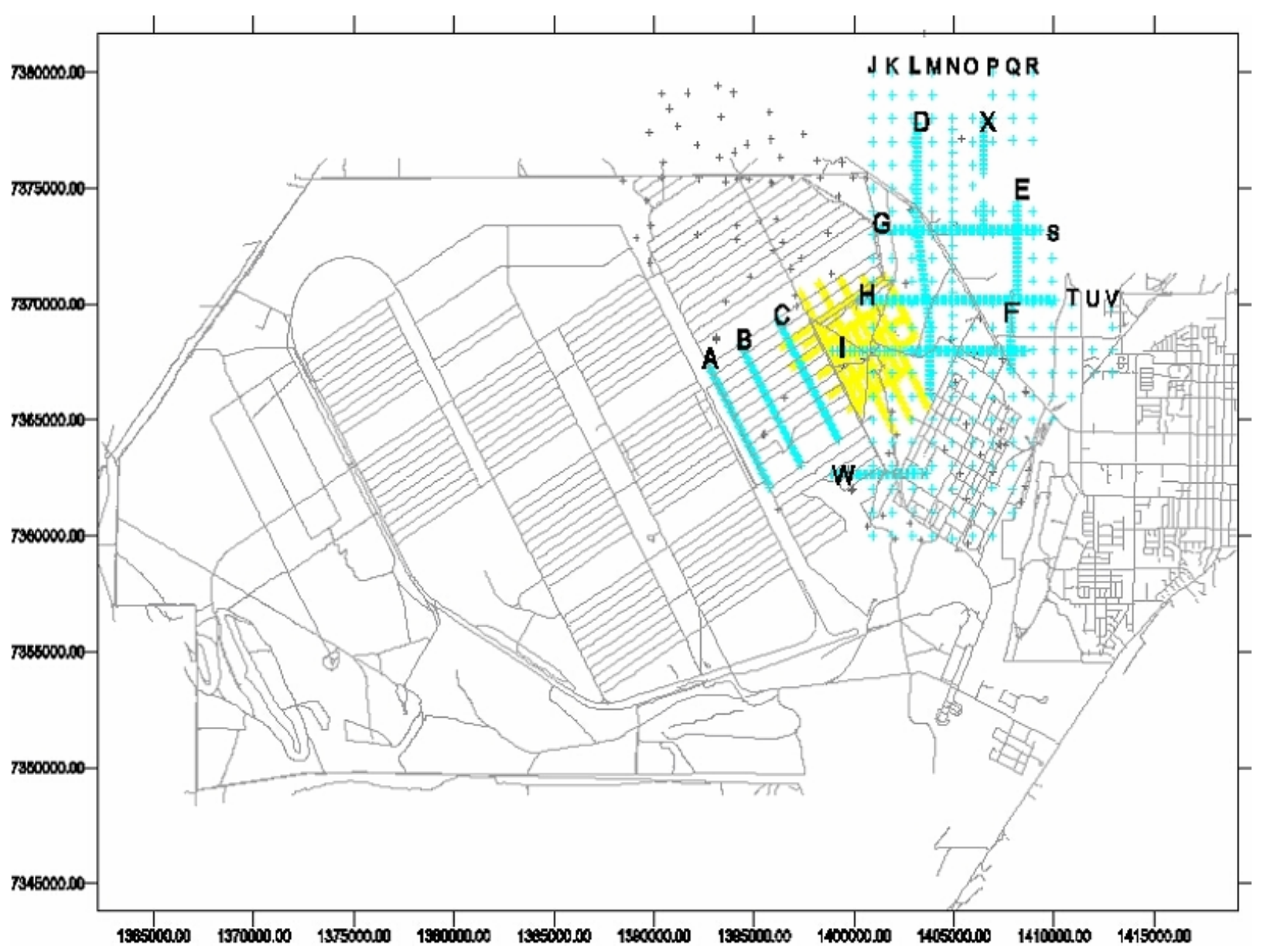

Figure B-1. AMT and gravity stations. AMT data acquired on lines A, C, D, E, F, G, H, I, X. Distance units are in feet. 


\section{TEAD Stratagem Data \\ Line A \\ Smooth 1-D Inversion}

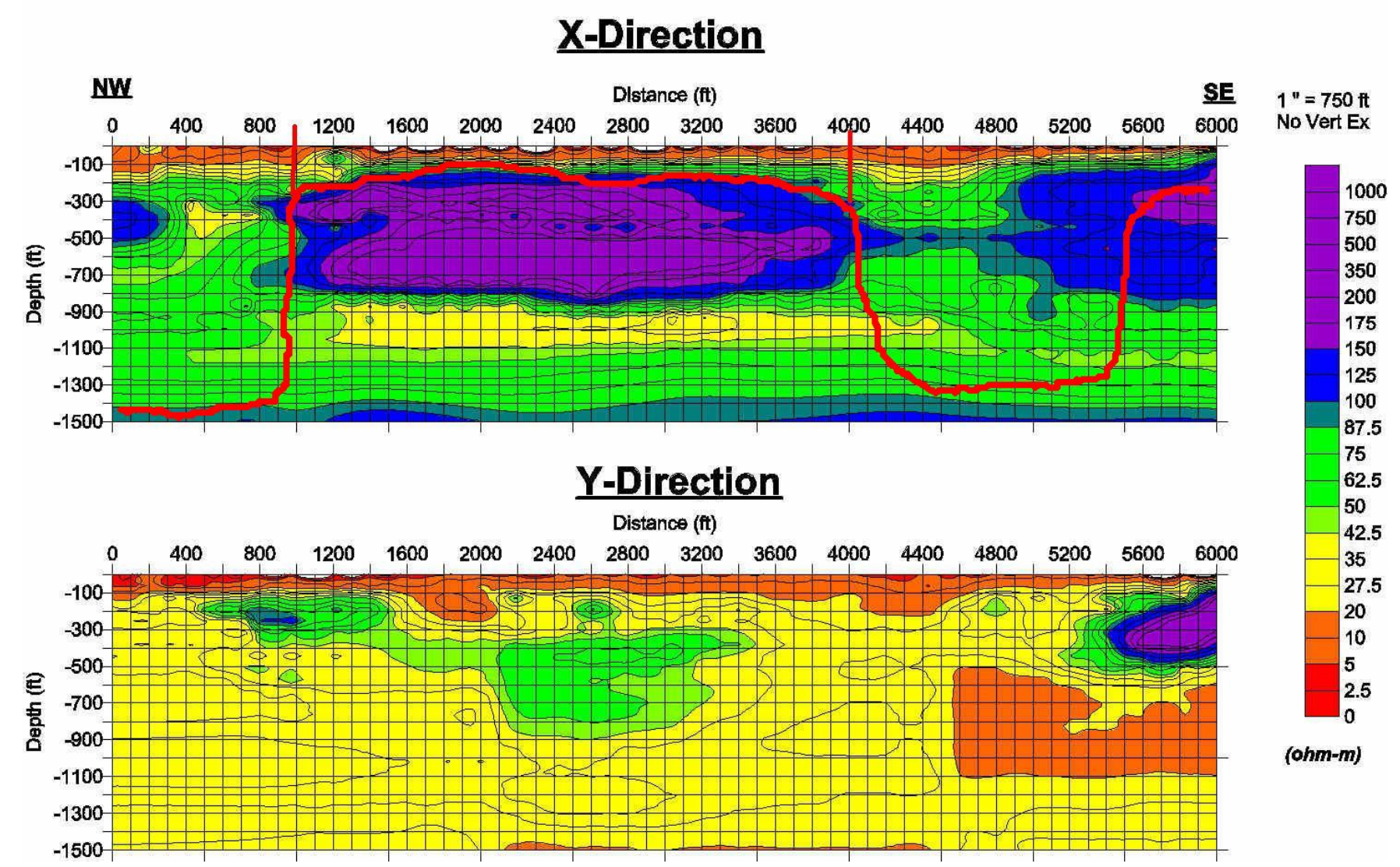

Figure B-2. 1-D AMT modeling results for Line A. Free-hand red line represents interpreted bedrock surface. Faults indicated by short, straight red lines. Distance and depth units are in feet. 


\section{TEAD Stratagem Data \\ Line C \\ Smooth 1-D Inversion}

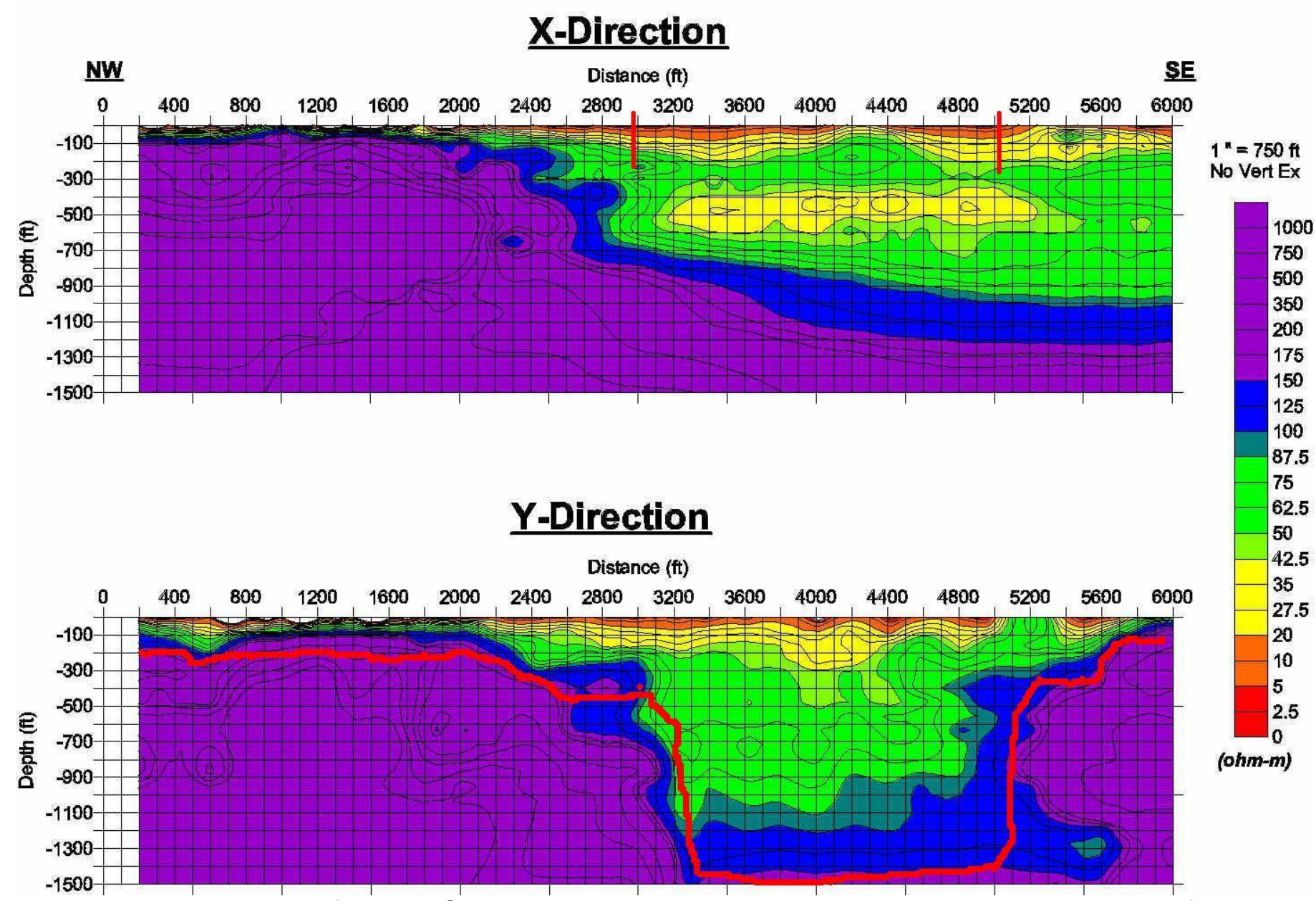

Figure B-3. 1-D AMT modeling results for Line C. Free-hand red line represents interpreted bedrock surface. Faults indicated by short, straight red lines. Distance and depth units are in feet. 


\section{TEAD Stratagem Data \\ Line D \\ Smooth 1-D Inversion}
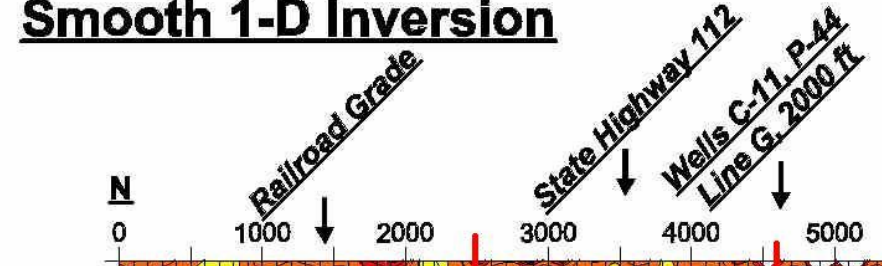

X-Direction

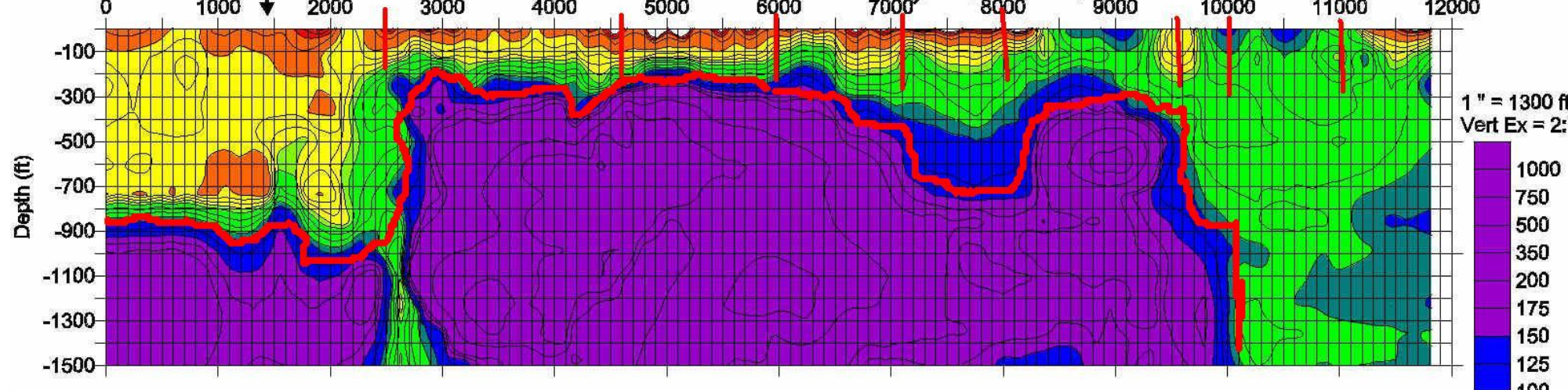

Y-Direction

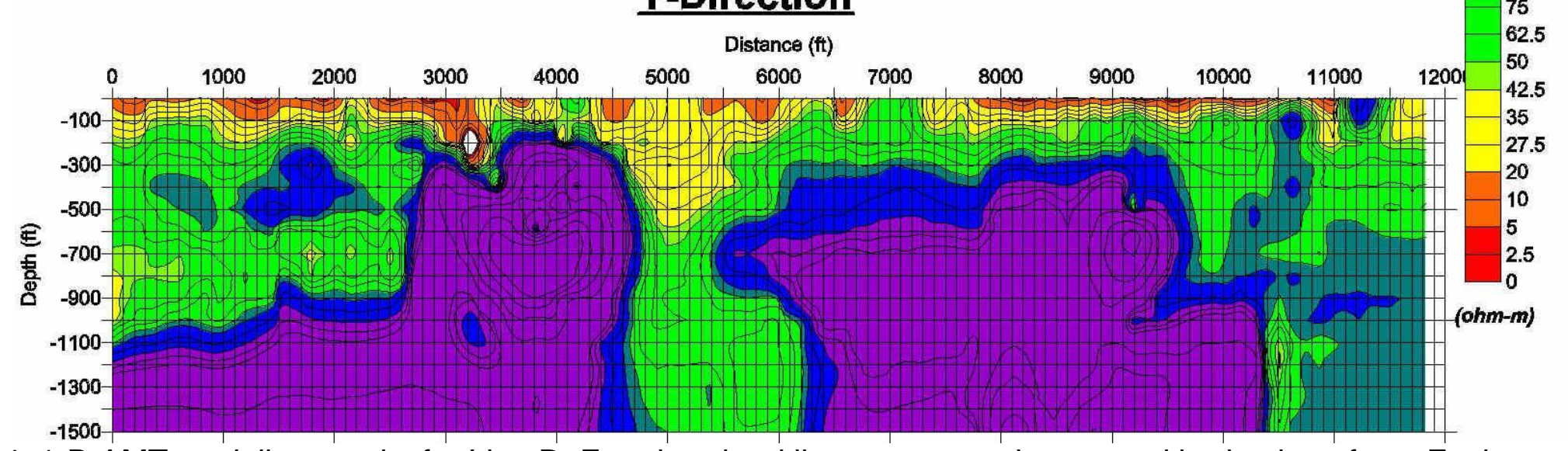

Figure B-4. 1-D AMT modeling results for Line D. Free-hand red line represents interpreted bedrock surface. Faults indicated by short, straight red lines. Distance and depth units are in feet. 


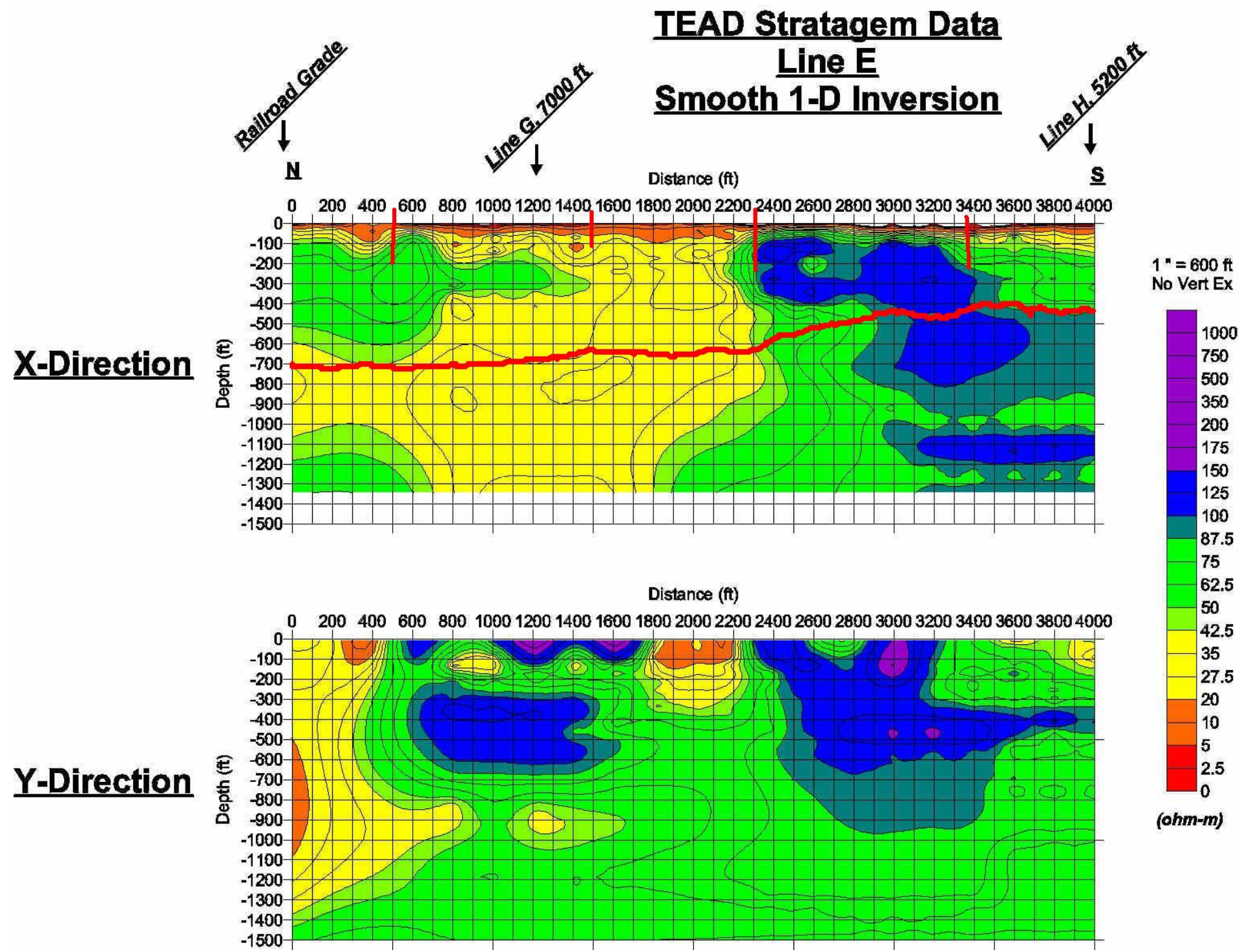

Figure B-5. 1-D AMT modeling results for Line E. Free-hand red line represents interpreted bedrock surface. Faults indicated by short, straight red lines. Distance and depth units are in feet. 


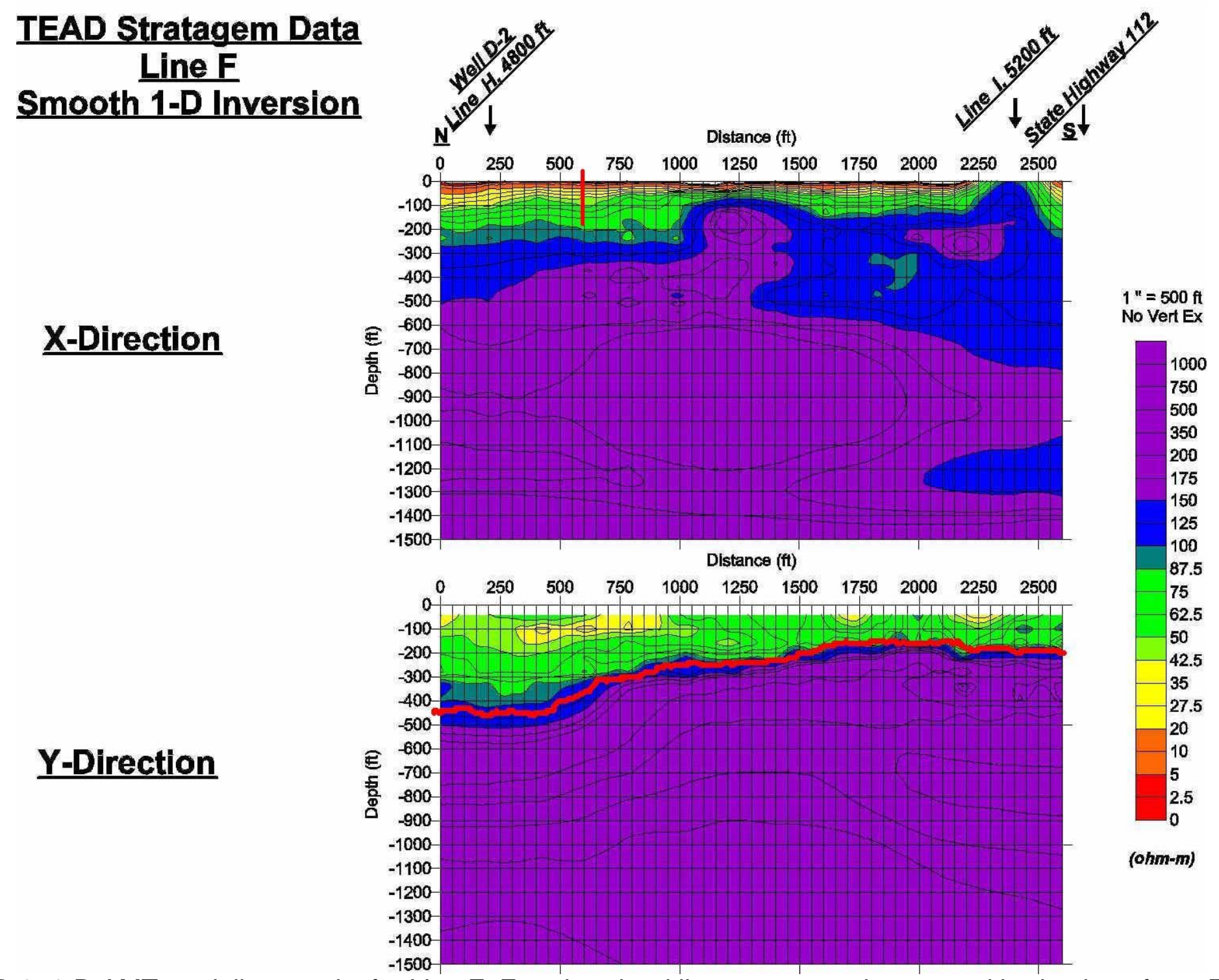

Figure B-6. 1-D AMT modeling results for Line F. Free-hand red line represents interpreted bedrock surface. Faults indicated by short, straight red lines. Distance and depth units are in feet. 


\section{TEAD Stratagem Data \\ Line G \\ Smooth 1-D Inversion}

$\underline{\text { X-Direction }}$

$$
\begin{array}{r}
-100 \\
-300 \\
-500 \\
\hline \text { E }-700 \\
\hline \text { 喜 }-900 \\
-1100 \\
-1300 \\
-1500
\end{array}
$$

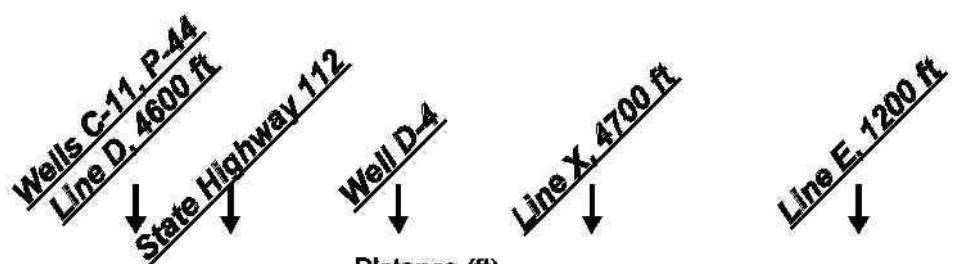

Distance (ft)

E $50010001500,200025003000350040004500 \quad 5000 \quad 5500 \quad 60006500700075008000$

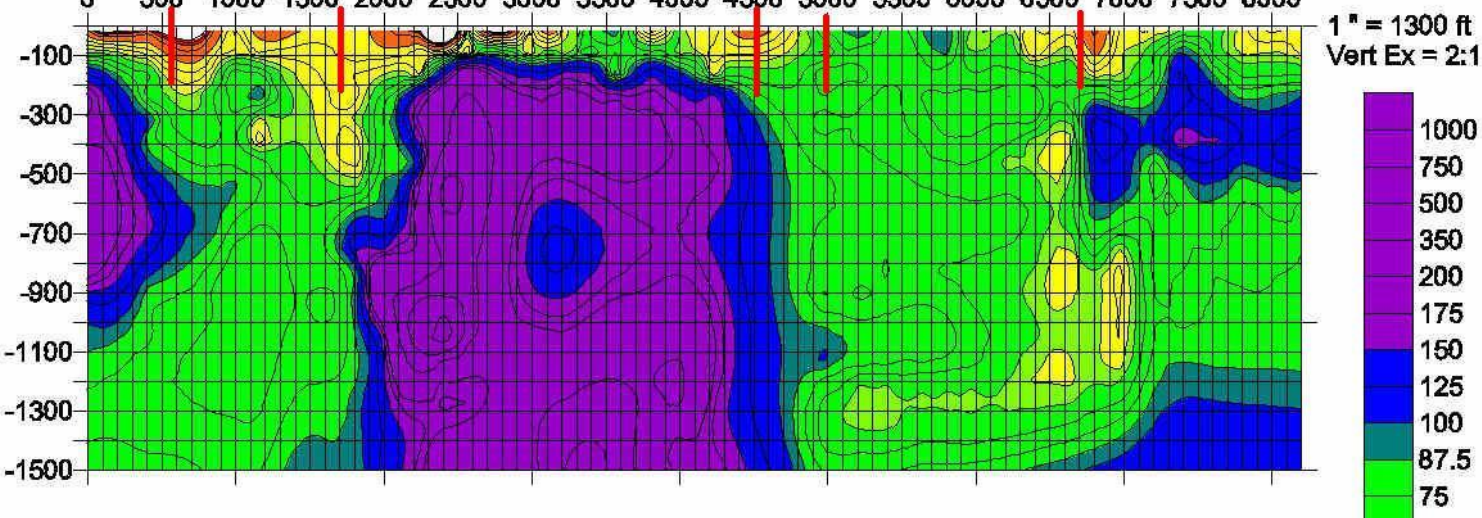

Distance (ft)

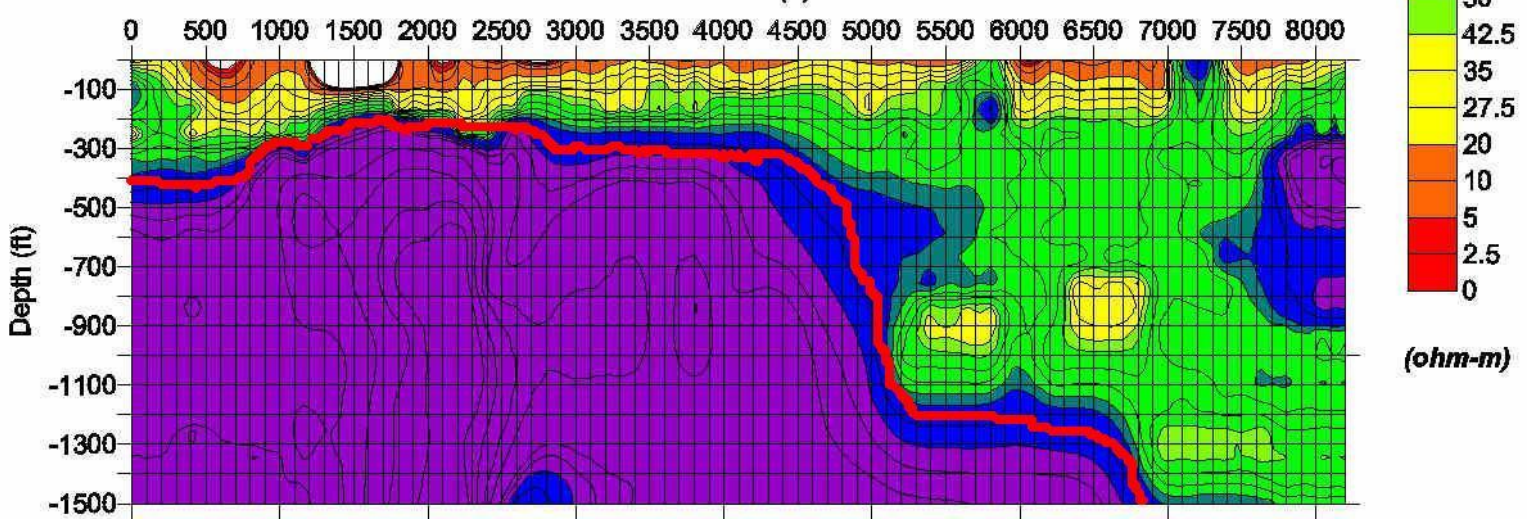

Figure B-7. 1-D AMT modeling results for Line G. Free-hand red line represents interpreted bedrock surface. Faults indicated by short, straight red lines. Distance and depth units are in feet. 


\section{TEAD Stratagem Data}

\section{Line $\mathrm{H}$}

\section{Smooth 1-D Inversion}

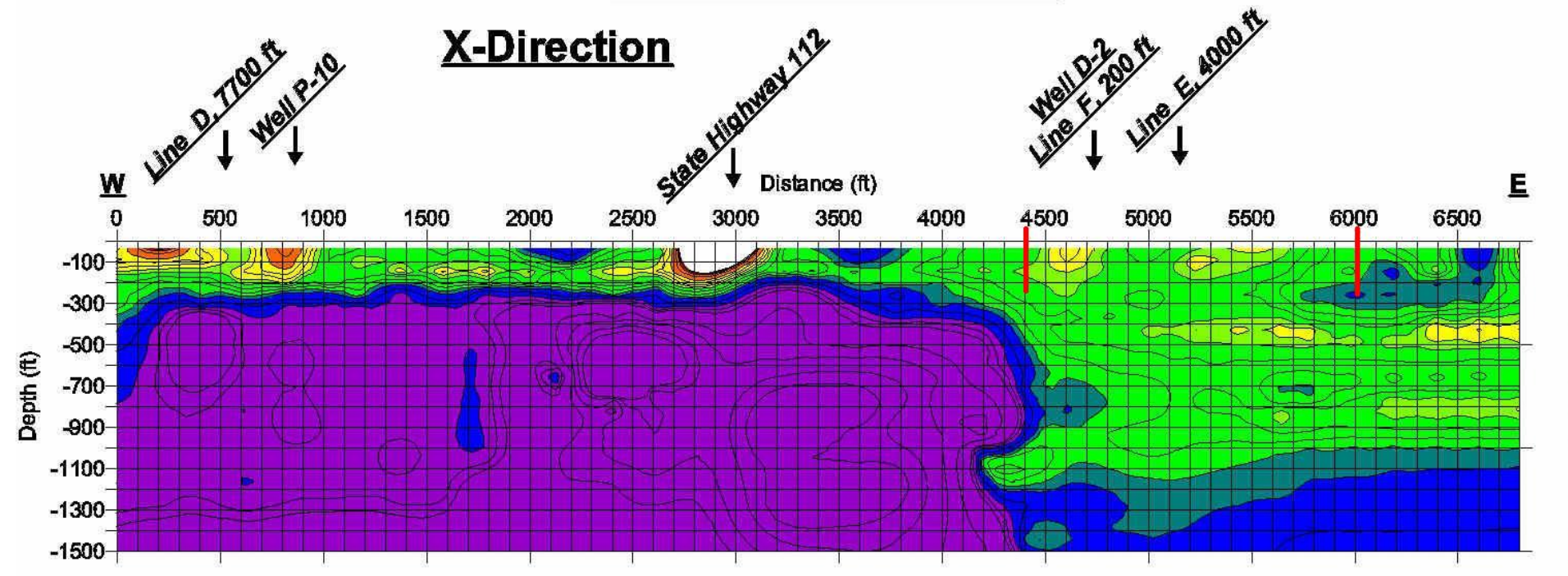

$1^{n}=750 \mathrm{ft}$ No Vert Ex

\section{Y-Direction}

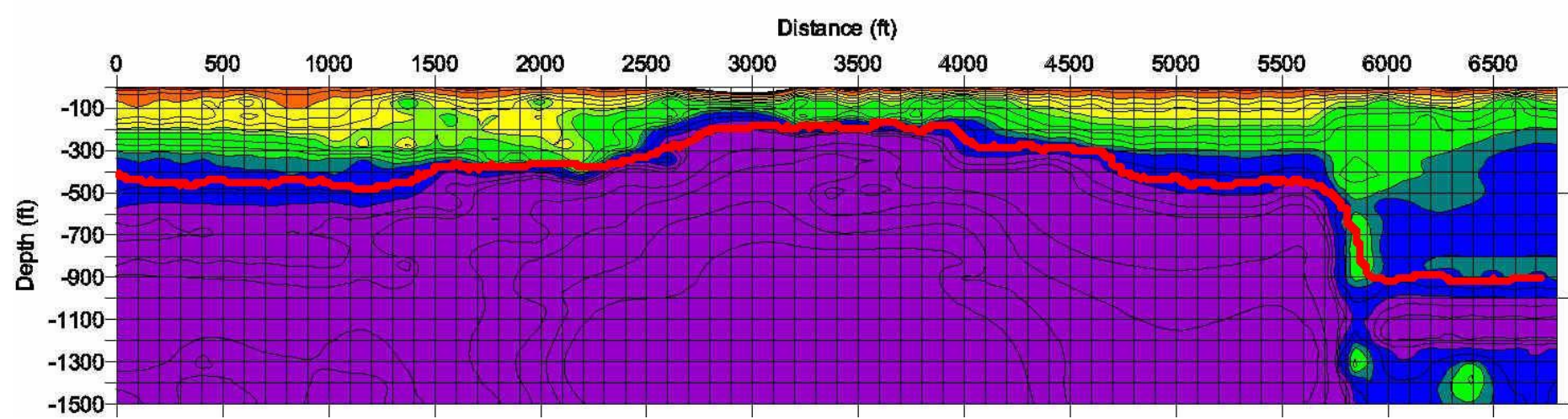

Figure B-8. 1-D AMT modeling results for Line H. Free-hand red line represents interpreted bedrock surface. Faults indicated by short, straight red lines. Distance and depth units are in feet. 
TEAD Stratagem Data

\section{Line I}

Smooth 1-D Inversion

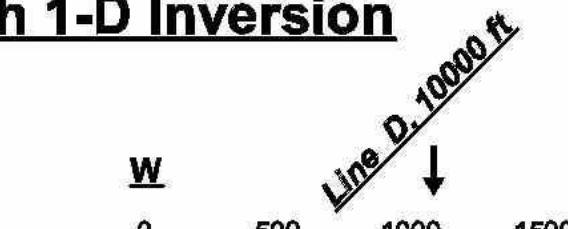

$\underline{\text { X-Direction }}$

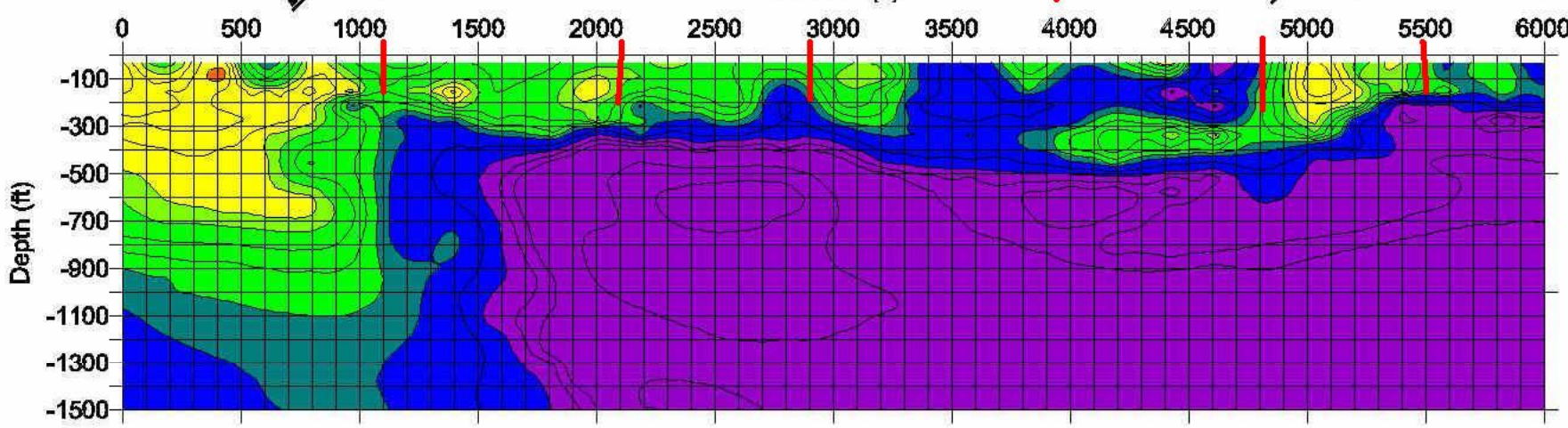

\section{$\underline{\text { Y-Direction }}$}

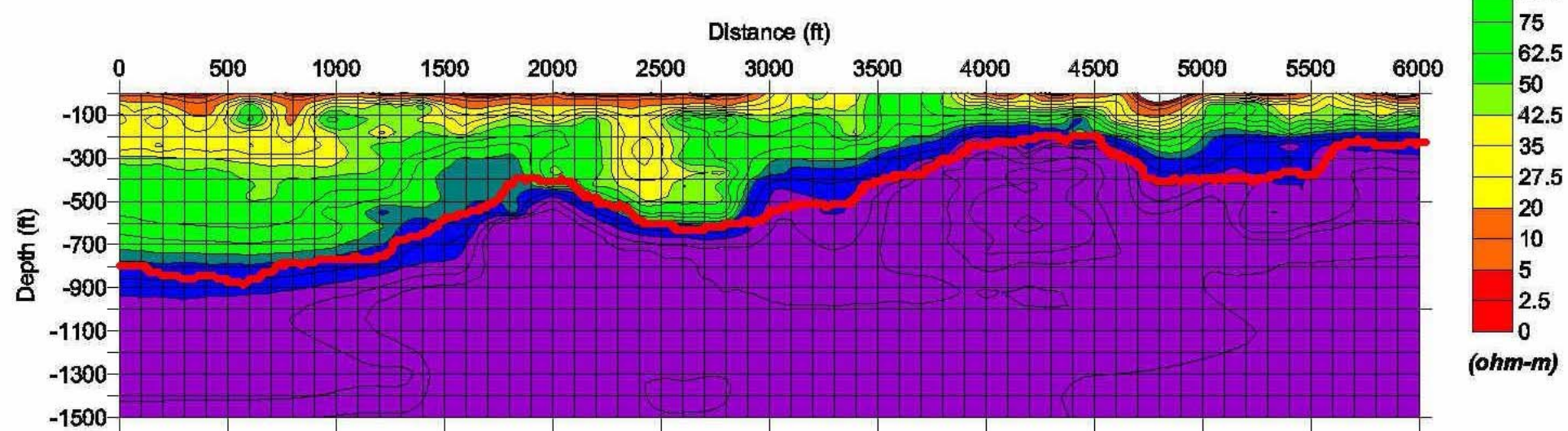

Figure B-9. 1-D AMT modeling results for Line I. Free-hand red line represents interpreted bedrock surface. Faults indicated by short, straight red lines. Distance and depth units are in feet. $1^{n}=750 \mathrm{ft}$ No Vert Ex

\section{0}




\section{TEAD Stratagem Data \\ Line X \\ Smooth 1-D Inversion}

\section{$\underline{\text { X-Direction }}$}

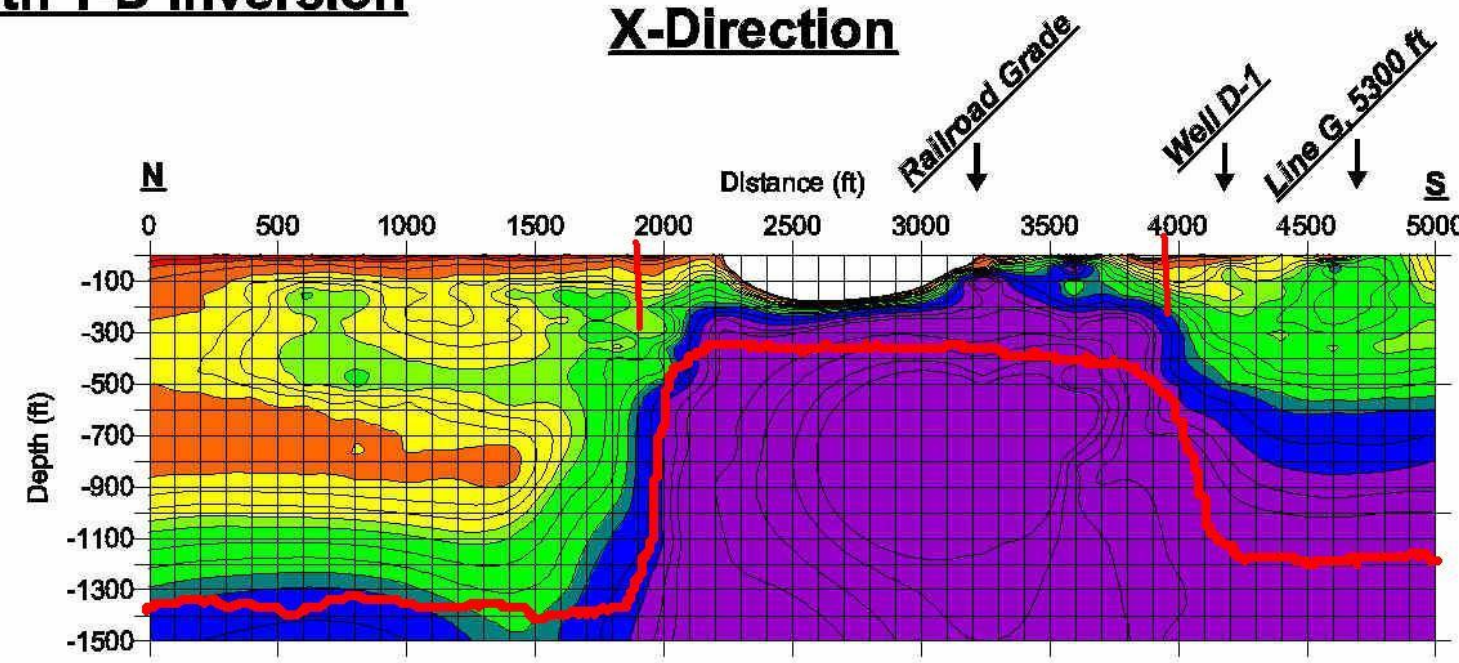

Y-Direction

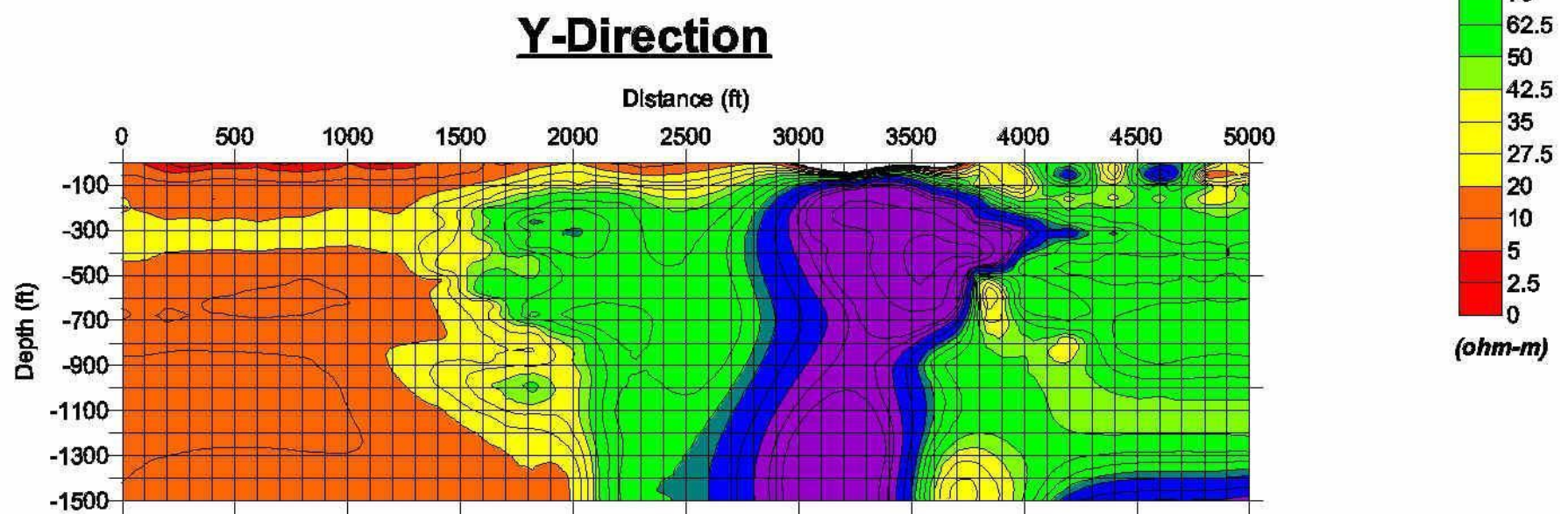

Figure B-10. 1-D AMT modeling results for Line X. Free-hand red line represents interpreted bedrock surface. Faults indicated by short, straight red lines. Distance and depth units are in feet. 


\section{APPENDIX C: 2-D AMT Modeling and Interpretation}

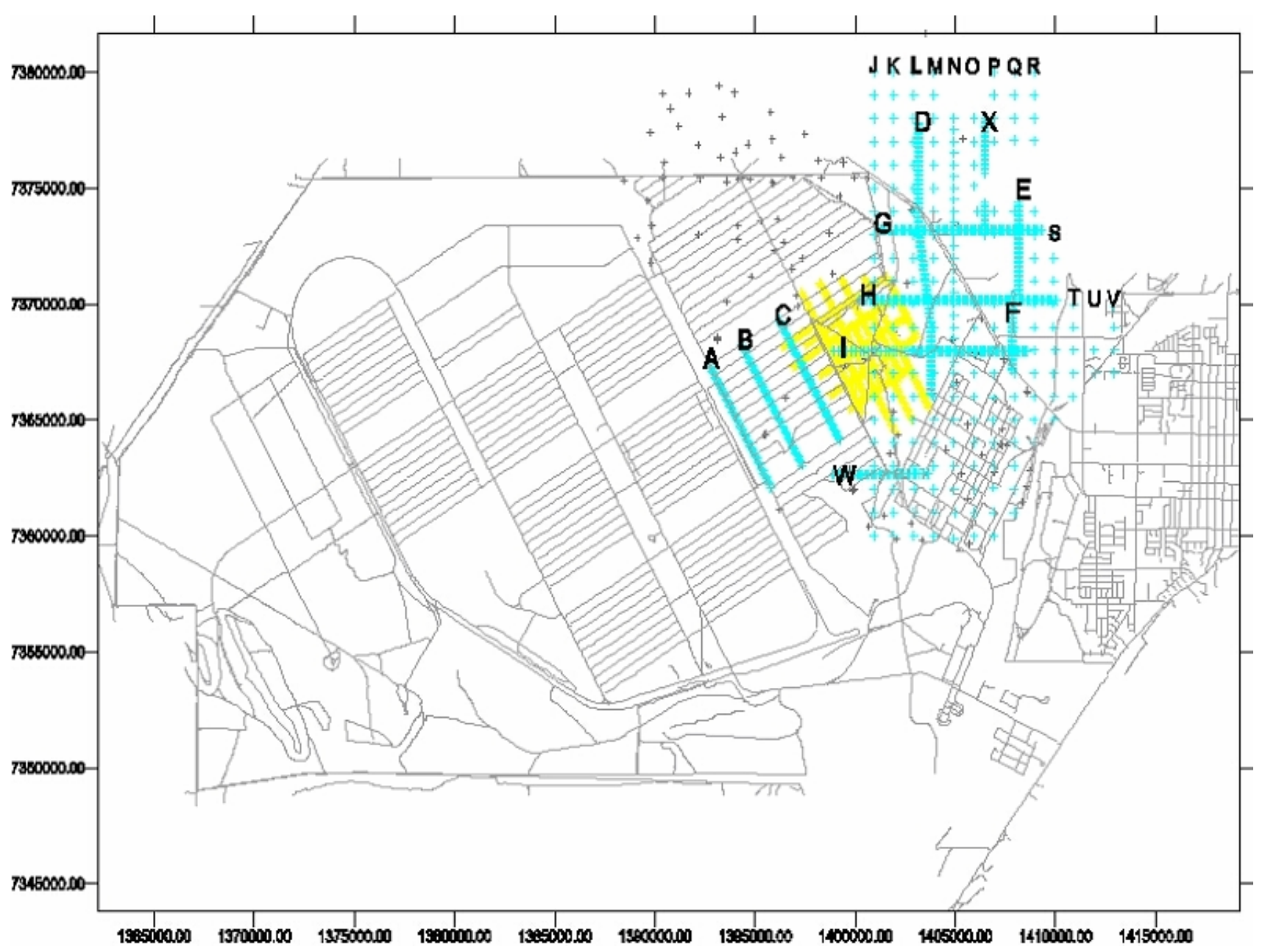

Figure C-1. AMT and gravity stations. AMT data acquired on lines A, C, D, E, F, G, H, I, X. 2-D interpretation for lines A and $C$ not presented here. Distance units are in feet. 


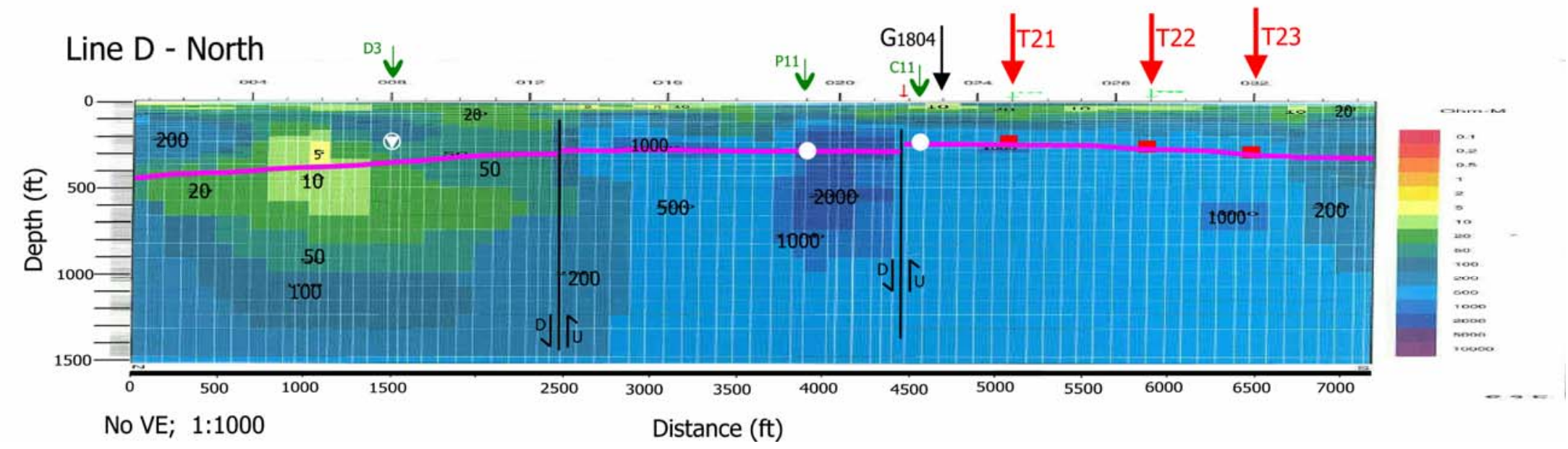

Figure C-2. 2-D AMT modeling results for Line D, northern half. Pink free-hand line represents interpreted bedrock surface. Faults indicated by black lines with displacement indicated. All white circles are boreholes (green) that hit bedrock. White inverted triangles are boreholes that did not intersect bedrock Red numbers and arrows are TEM stations. "G1804" is distance along Line G where D crossed. Distance and depth units are in feet. Distance and depth units are in feet. 


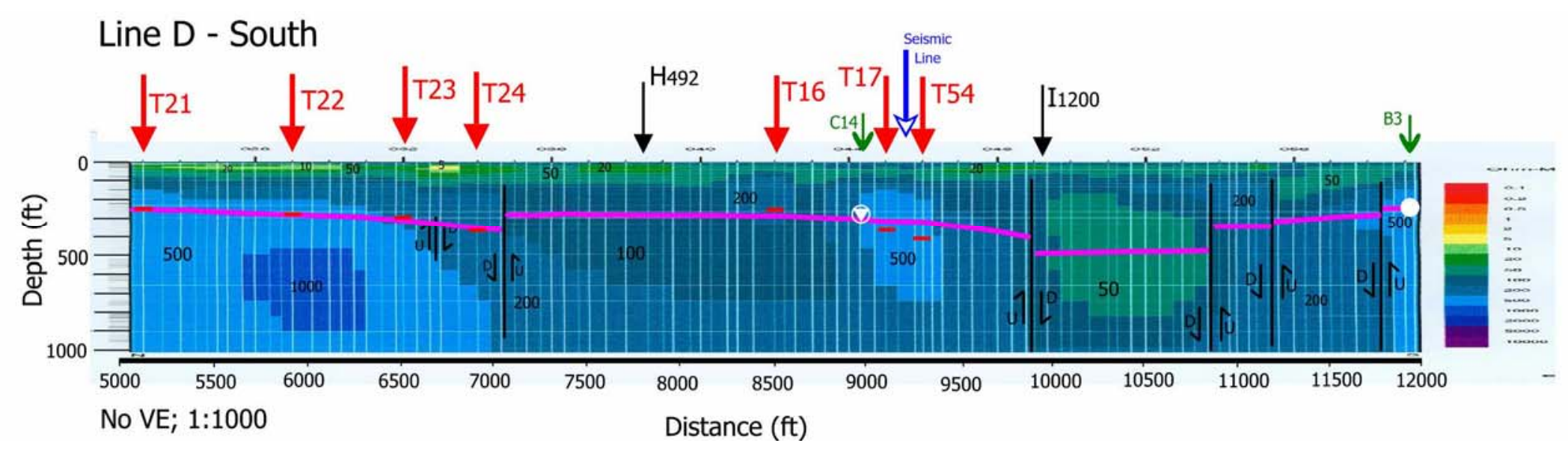

Figure C-3. 2-D AMT modeling results for Line D, southern half. Pink free-hand line represents interpreted bedrock surface. Faults indicated by black lines with displacement indicated. All white circles are boreholes (green) that hit bedrock. White inverted triangles are boreholes that did not intersect bedrock Red numbers and arrows are TEM stations. Red bars within section are TEM interpreted bedrock depths. "I1200" is distance along Line I where D crossed. Location of where seismic line is crossed is in blue. Distance and depth units are in feet. 


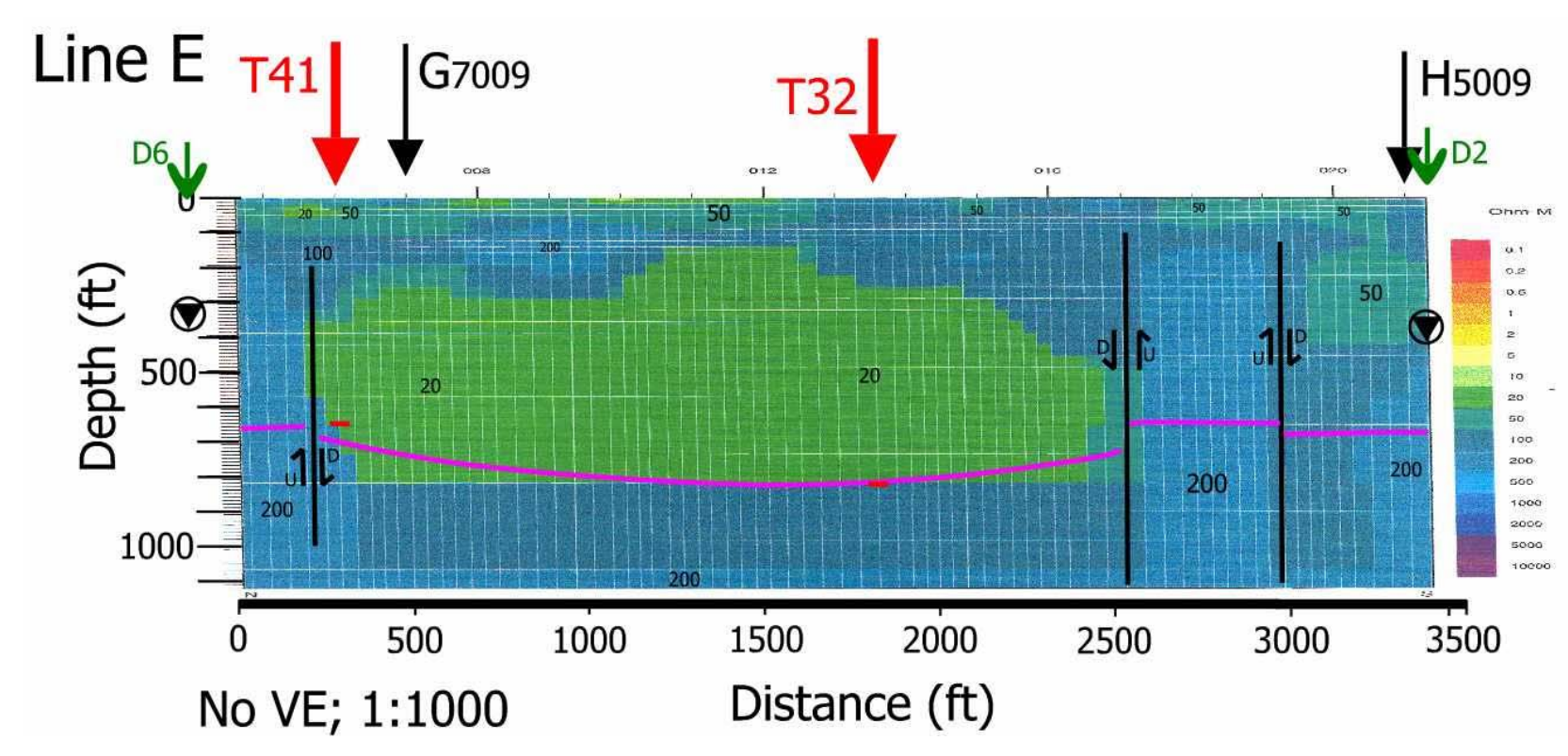

Figure C-4. 2-D AMT modeling results for Line E. Pink free-hand line represents interpreted bedrock surface. Faults indicated by black lines with displacement indicated. All white circles are boreholes (green) that hit bedrock. White inverted triangles are boreholes that did not intersect bedrock Red numbers and arrows are TEM stations. Red bars within section are TEM interpreted bedrock depths. "G7009" is distance along Line G where E crossed. Distance and depth units are in feet. 


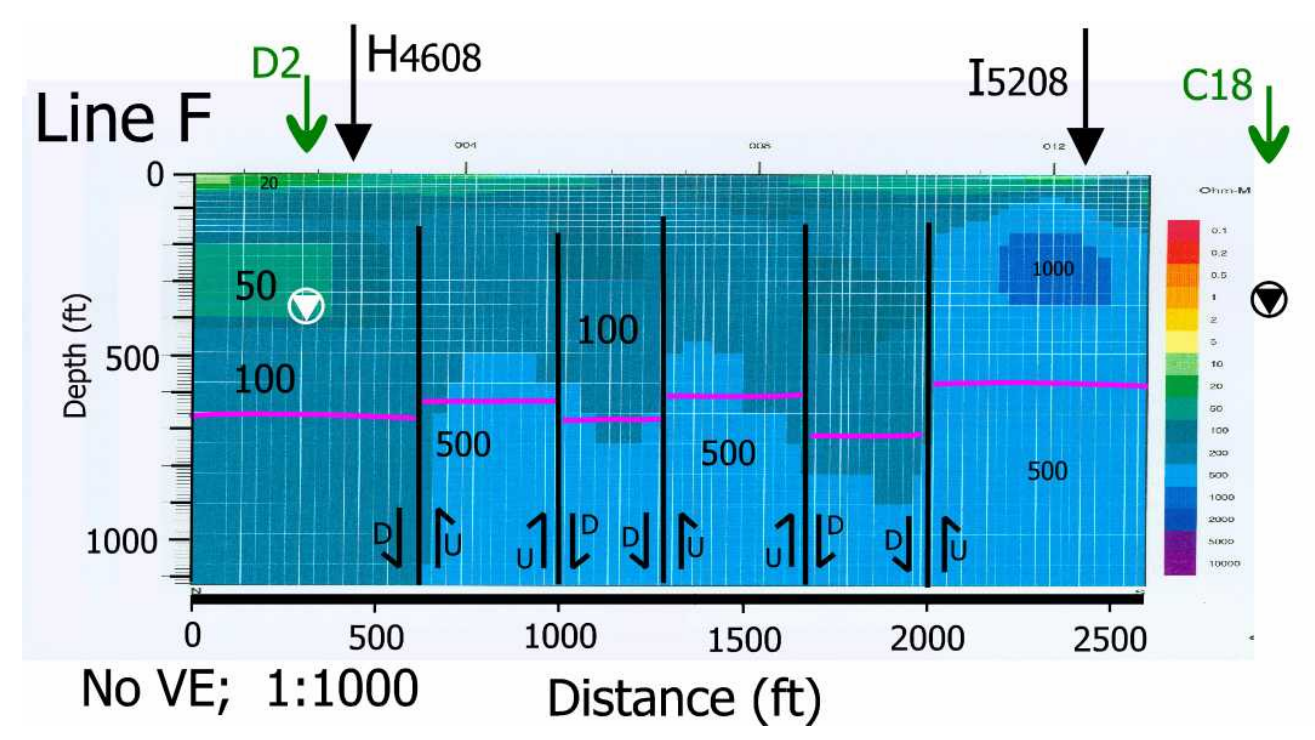

Figure C-5. 2-D AMT modeling results for Line F. Pink free-hand line represents interpreted bedrock surface. Faults indicated by black lines with displacement indicated. All white circles are boreholes (green) that hit bedrock. White inverted triangles are boreholes that did not intersect bedrock " $\mathrm{H} 4608$ " is distance along Line $\mathrm{H}$ where $\mathrm{F}$ crossed. Distance and depth units are in feet. 


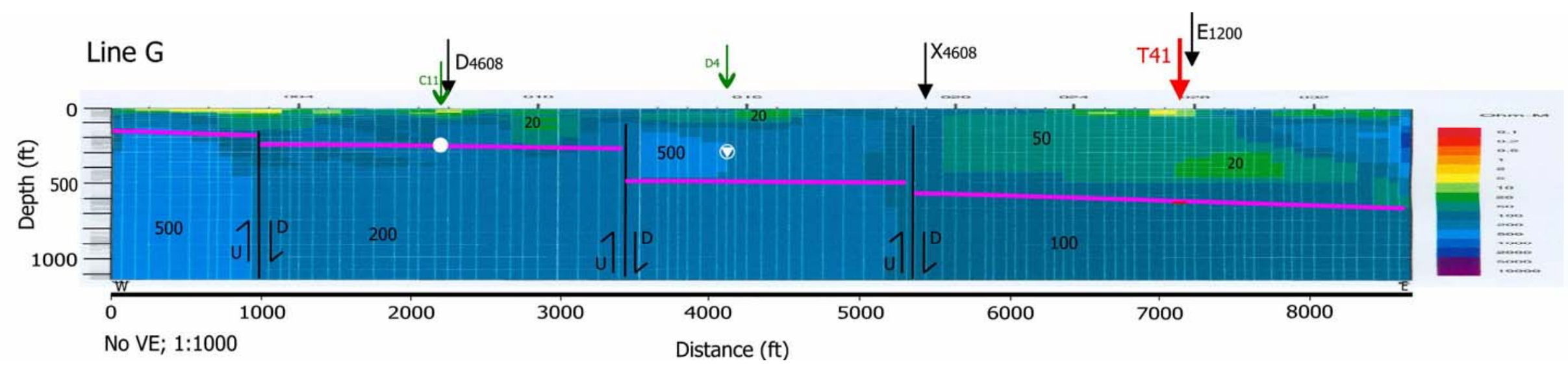

Figure C-6. 2-D AMT modeling results for Line G. Pink free-hand line represents interpreted bedrock surface. Faults indicated by black lines with displacement indicated. All white circles are boreholes (green) that hit bedrock. White inverted triangles are boreholes that did not intersect bedrock Red numbers and arrows are TEM stations. Red bars within section are TEM interpreted bedrock depths. "E1200" is distance along Line E where G crossed. Distance and depth units are in feet. 


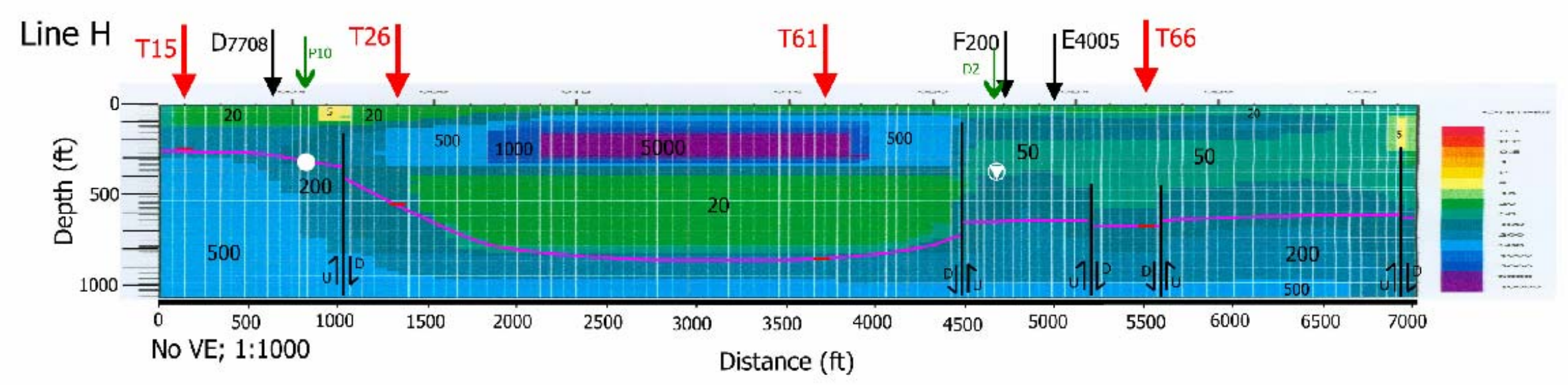

Figure C-7. 2-D AMT modeling results for Line H. Pink free-hand line represents interpreted bedrock surface. Faults indicated by black lines with displacement indicated. All white circles are boreholes (green) that hit bedrock. White inverted triangles are boreholes that did not intersect bedrock Red numbers and arrows are TEM stations. Red bars within section are TEM interpreted bedrock depths. "E4005" is distance along Line E where H crossed. AMT data was not collected on the western end of the line. Distance and depth units are in feet. 


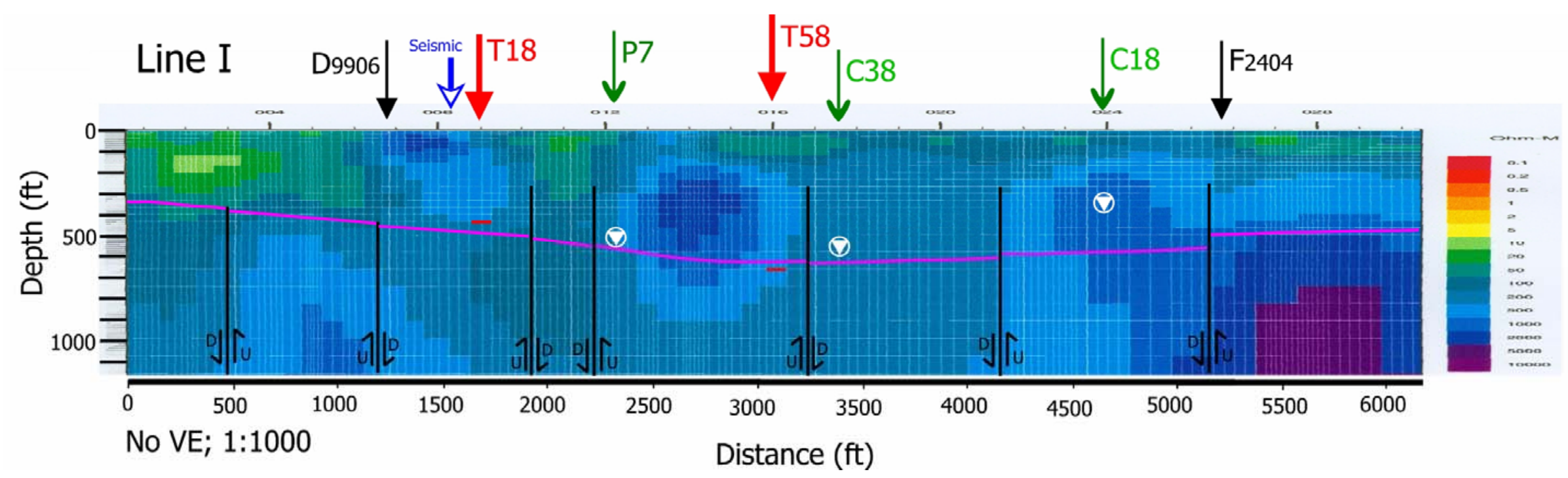

Figure C-8. 2-D AMT modeling results for Line I. Pink free-hand line represents interpreted bedrock surface. Faults indicated by black lines with displacement indicated. White inverted triangles are boreholes (green) that did not intersect bedrock Red numbers and arrows are TEM stations. Red bars within section are TEM interpreted bedrock depths. "F 2404 " is distance along Line F where I crossed. Blue arrow is where seismic line crossed Line I. AMT data was not collected on the western end of the line. Distance and depth units are in feet. 


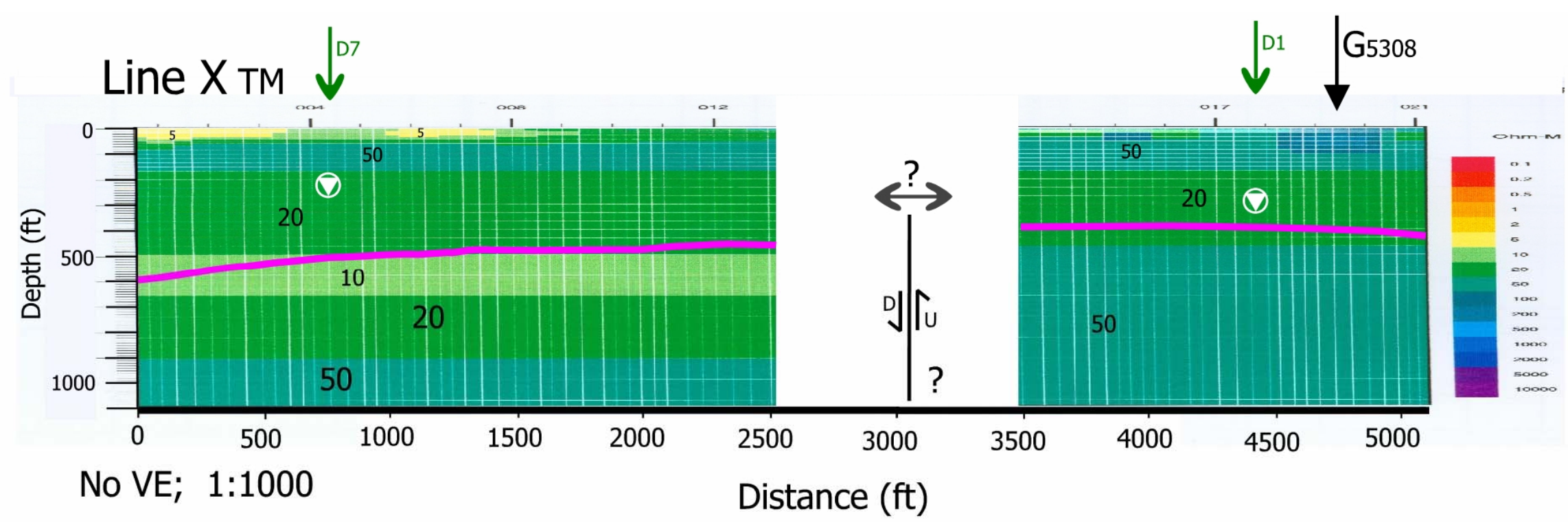

Figure C-9. 2-D AMT modeling results for Line X. Pink free-hand line represents interpreted bedrock surface. Faults indicated by black lines with displacement indicated. White inverted triangles are boreholes (green) that did not intersect bedrock "G5308" is distance along Line G where X crossed. Distance and depth units are in feet. 